HETEROCYCLES, Vol. 89, No. 10, 2014, pp. 2271 - 2302. @ 2014 The Japan Institute of Heterocyclic Chemistry Received, 19th August, 2014, Accepted, 22nd September,2014, Published online, 25th September, 2014 DOI: $10.3987 / R E V-14-805$

\title{
SYNTHETIC APPROACHES TO SPIRO-OXINDOLES AND IMINOINDOLINES BASED ON FORMATION OF C2-C3 BOND
}

\section{Chihiro Tsukano and Yoshiji Takemoto*}

Graduate School of Pharmaceutical Sciences, Kyoto University, Yoshida, Sakyo-ku, Kyoto, 606-8501, Japan, Takemoto@pharm.kyoto-u.ac.jp

\begin{abstract}
Spirooxindole and iminoindoline structures can be found in a wide range of complex natural products, and compounds containing these groups invariably display interesting biological activities. Considering their interesting biological properties and complex architecture, significant research efforts have been directed towards developing new synthetic methods for constructing these structures. This review summarizes our studies towards developing novel synthetic strategies capable of accessing these structures, as well as the applications of these methods to synthesizing natural products, including elacomine and dehaloperophoramidine.
\end{abstract}

\section{CONTENTS}

1. Spirooxindole

1-1. Reported Synthetic Methods for Spirooxindole by Forming C2-C3 Bond

1-2. Our Synthetic Strategies

1-3. Construction of Spirooxindole Skeleton by Domino Cyclization

1-4. Formal Synthesis of Elacomine by the Domino Palladium(0)-Catalyzed Spirooxindole Formation

1-5. Synthesis of Spirooxindoles using Silyl Amidation

2. Synthetic Studies on 2-Iminoindoline

2-1. Reported Synthetic Methods for Constructing 2-Iminoindolines and Related Compounds

2-2. $\mathrm{SmI}_{2}$-Mediated Reductive Cyclization of Carbodiimides for Synthesis of Spiro-2-Iminoindolines

2-3. Synthetic Studies of Perophoramidine

3. Summary 


\section{SPIROOXINDOLE}

The spirooxindole structure (1) is found in many complex natural products, and several compounds containing a spirooxindole moiety have been reported to possess interesting biological properties (Figure 1). ${ }^{1}$ For example, prosurugatoxin $(2),{ }^{2}$ alstonisine $(3)^{3}$ and spirotryprostatin A (4), ${ }^{4}$ which are complex pentacyclic indole alkaloids bearing contiguous stereocenters, have been reported to exhibit anti-nicotinic, moderate in vitro antiplasmodial, and antimitotic activities, respectively. The related compounds scholarisine A (5) and arbophylline (6), however, have not been reported to possess any interesting biological properties, ${ }^{5,6}$ although these molecules have captured the attention of synthetic chemists all over the world because of their unusual cage-like structures. Interestingly, various spiro-ring systems have been reported in spirooxindole natural products, such as those fused with pyrrolidine [e.g., alstonisine (3), spirotryprostatin A (4), and elacomine $\left.(7)^{7}\right]$, piperidine [e.g., tabernoxidine $(9)^{8}$ ], five- and six-membered carbocycles [e.g., prosurgatoxin (2) and gelsemine $(\mathbf{1 0})^{9}$ ], and six-membered oxacycles [e.g., scholarisine A (5) and arbophylline (6)]. The spirooxindole structure is also an important pharmacophore in medicinal chemistry, ${ }^{10}$ and structures of this type can also be used as intermediates for synthesizing other indole alkaloids. Considering their numerous applications and interesting properties, there has been significant interest in developing new methods for the construction of spirooxindoles from researchers working in both synthetic and medicinal chemistry.
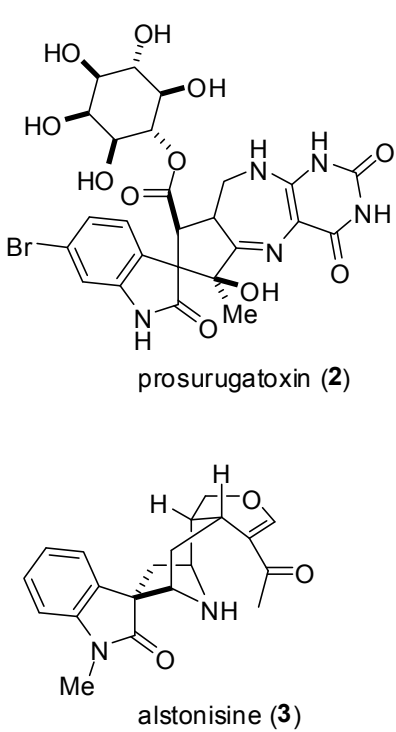
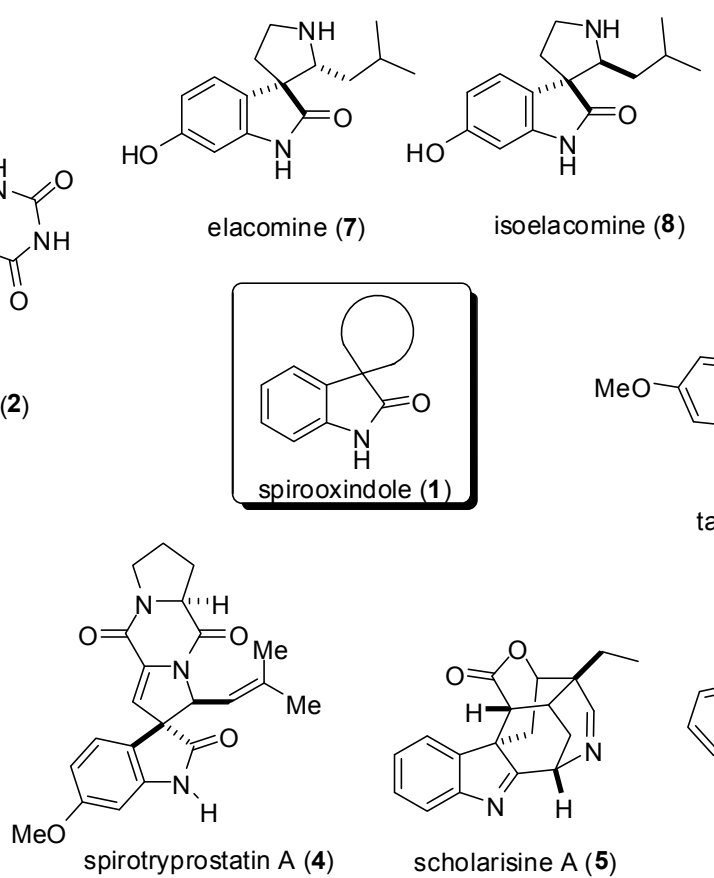
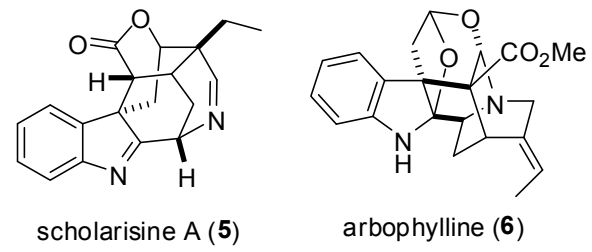

Figure 1. 3,3'-Pyrrolidinyl-spirooxindole-type natural products 


\section{1-1. REPORTED SYNTHETIC METHODS FOR SPIROOXINDOLE BY FORMING C2-C3 BOND}

A variety of methods have been reported for synthesizing spirooxindoles, ${ }^{11}$ and these methods can be divided into two categories, including (i) stepwise synthesis involving the formation of the oxindole ring followed by the construction of the spiro-ring system, and (ii) direct synthesis involving the simultaneous construction of the two rings making up the spiro-ring system. 3,3-Disubstituted oxindoles are quite often employed as synthetic intermediates for the stepwise synthesis of spirooxindoles because a variety of methods, including asymmetric procedures, have been developed for the synthesis of these compounds. However, the development of a direct method for the simultaneous construction of a spiro-center and an oxindole skeleton would be desirable from the perspective of synthetic efficiency. Murphy ${ }^{12}$ and Overman $^{13}$ reported the development of an elegant one-step procedure for synthesizing the spiro[indoline-3,3'-pyrrolidine] skeleton using a radical-mediated or palladium-catalyzed tandem cyclization and intramolecular trapping reaction. Several other methods have also been reported for constructing spirooxindole structures in a single step, including oxidative rearrangement, ${ }^{14}$ Heck, ${ }^{15}$ intramolecular Mannich, ${ }^{16}$ ring expansion, ${ }^{17}$ and 1,3-dipolar cycloaddition ${ }^{18}$ reactions. Despite the large number of methods that have been reported in this area, research towards developing new methods for constructing spirooxindoles continues to attract considerable attention.

\section{1-2. OUR SYNTHETIC STRATEGIES}

We developed a cyanoamidation process for synthesizing 3,3-disubstituted oxindoles, which involved the formation of the $\mathrm{C} 2-\mathrm{C} 3$ bond (Scheme 1). ${ }^{19}$ The reaction of compound 11 with $\mathrm{Pd}\left(\mathrm{PPh}_{3}\right)_{4}$ in xylene at $130{ }^{\circ} \mathrm{C}$ proceeded regioselectively to give 3,3-disubstituted oxindole 12 without any of the six membered lactam. ${ }^{19 a, b}$ We also developed an enantioselective version of this cyanoamidation process using $\mathrm{Pd}(\mathrm{dba})_{2}$ with the chiral phosphoramidite 13 and $N, N$-dimethylpropylene urea (DMPU). ${ }^{19 \mathrm{c}, \mathrm{d}}$ It was envisaged that several new approaches could be developed for constructing the spirooxindole skeleton by extending the idea of the cyanoamidation reaction used for the formation of the $\mathrm{C} 2-\mathrm{C} 3$ bond, including (i) a domino reaction for the construction of the spiro-ring system; and (ii) a stepwise reaction for constructing various spiro-ring systems (Scheme 2). The first half of this review has been focused on our most recent research efforts that explore these two strategies and their application to the synthesis of natural products. ${ }^{20-22}$

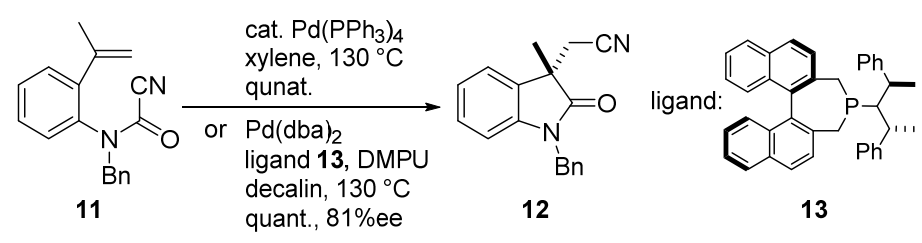

Scheme 1. Synthesis of 3,3-disubstituted oxindole by cyanoamidation 


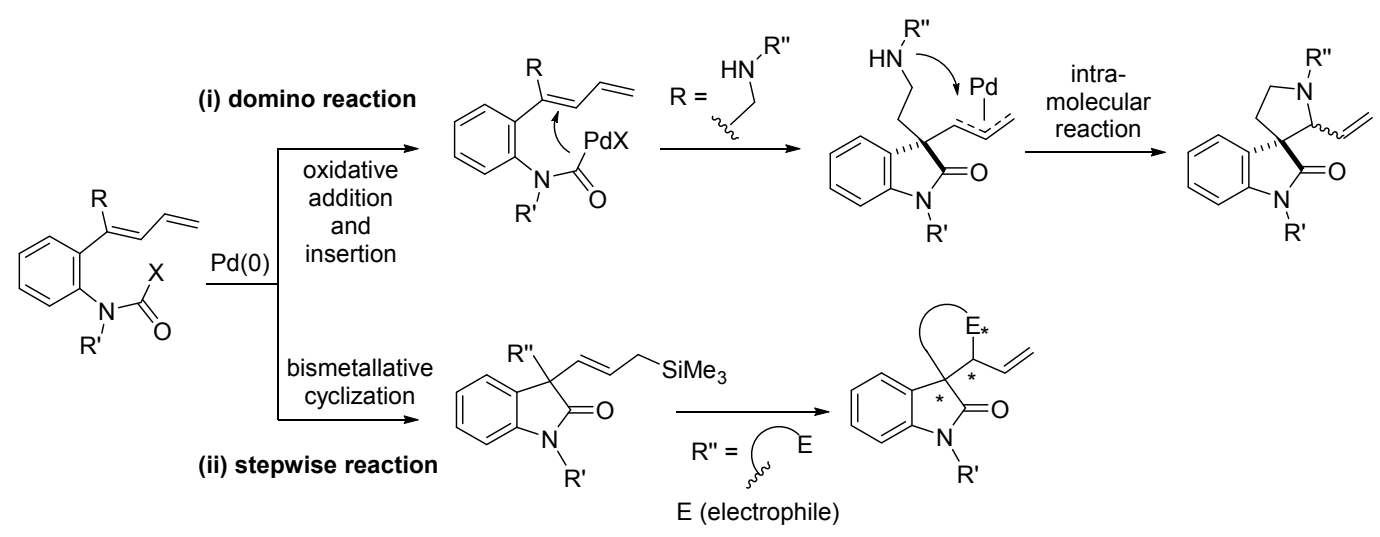

Scheme 2. Synthetic strategy for spirooxindoles

\section{1-3. CONSTRUCTION OF SPIROOXINDOLE SKELETON BY DOMINO CYCLIZATION}

When we started our research towards developing of a novel domino reaction strategy for constructing spirooxindole skeletons, we had already developed a palladium catalyzed cyanoamidation process for constructing 3,3-disubstituted oxindoles from 2-(alkenyl)phenylcarbamoyl cyanide 11, as described above (Scheme 1). ${ }^{19}$ However, this cyanoamidation reaction only worked for substrates bearing a terminal olefin, which represented a major limitation for this transformation. It was envisaged that the use of a diene instead of a terminal olefin would allow 13 to react to give the $\pi$-allylpalladium intermediate $17,{ }^{23}$ which could be converted to the spirooxindole $\mathbf{1 8}$ by a trapping reaction involving an intramolecular nucleophile (Scheme $3) .{ }^{24}$ With this in mind, we focused our initial efforts on the development of a palladium catalyzed cyclization reaction for carbamoyl chlorides such as $\mathbf{1 3}(\mathrm{X}=\mathrm{Cl})$ bearing a 1,3-diene moiety. ${ }^{25}$

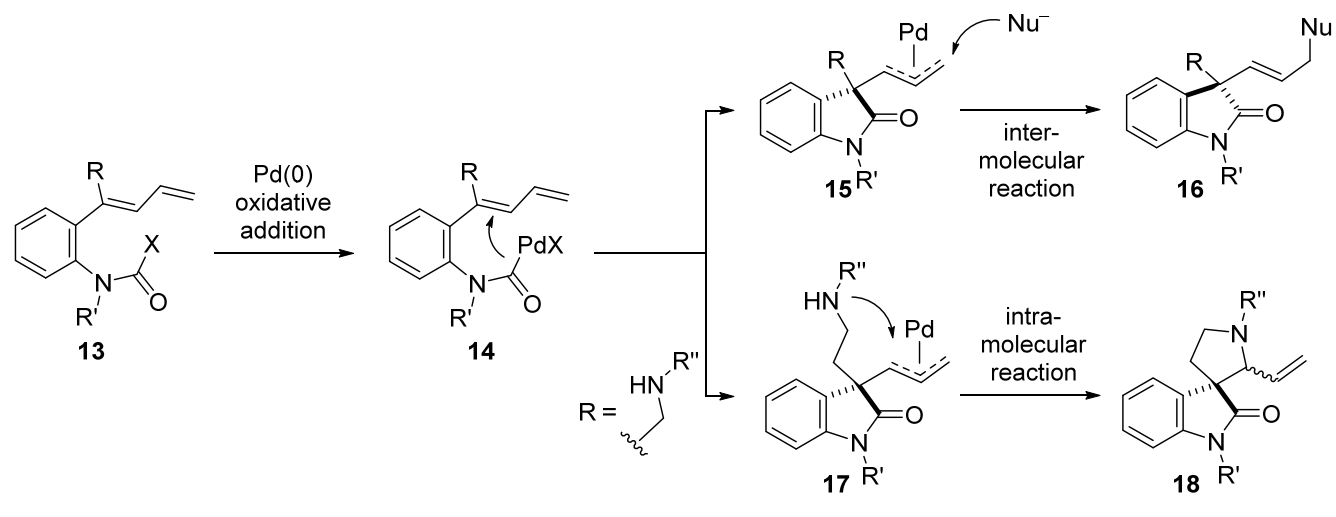

Scheme 3. Synthetic strategy for constructing the contiguous stereogenic centers of spirocyclic compounds

We initially examined an intermolecular reaction to determine the most appropriate nucleophiles for the effective trapping of the $\pi$-allylpalladium intermediate. The treatment of carbamoyl chlorides $\mathbf{1 9}$ bearing a diene moiety with a catalytic amount of palladium acetate $\left(\mathrm{Pd}(\mathrm{OAc})_{2}\right)$, triphenylphosphine $\left(\mathrm{PPh}_{3}\right)$ and cesium carbonate $\left(\mathrm{Cs}_{2} \mathrm{CO}_{3}\right)$ gave the corresponding $\pi$-allylpalladium intermediates, which were trapped 
with several nucleophiles (Table 1). As expected, the reaction with $p-\mathrm{NsNH}_{2}$ proceeded smoothly to give the 1,4-adduct 20a via the corresponding $\pi$-allylpalladium intermediate, with none of the 1,2-adducts observed (Table 1, entry 1). Two other sulfonamides, $\mathrm{TsNH}_{2}$ and $\mathrm{TfNH}_{2}$, were also used as nucleophiles the reaction, resulting in the formation of oxindoles $20 \mathrm{~b}$ and 20c (Table 1, entries 2 and 3). Although the reactions of 19 with morpholine and aniline gave the corresponding ureas 21d and 21e instead of the cyclized products $20 \mathbf{d}$ and $20 \mathrm{e}$, the use of indole as a nitrogen nucleophile resulted in the successful formation of the cyclized product $20 \mathrm{f}$ (Table 1, entries 4-6). Interestingly, the $\pi$-allylpalladium intermediate also reacted with phenol and benzoic acid, which are both only weakly nucleophilic, to give the corresponding oxindoles $\mathbf{2 0 g}$ and $\mathbf{2 0 h}$ in $81 \%$ and $74 \%$ yields, respectively (Table 1, entries 7 and 8). Furthermore, the $\pi$-allylpalladium intermediate could be trapped with organoboronic acids under the same reaction conditions to give the corresponding arylated and alkenylated adducts $20 \mathbf{i}$ and $\mathbf{2 0 j}$ (Table 1 , 9 and 10).

Table 1. Synthesis of 3,3-disubstituted oxindole by palladium(0)-catalyzed amidation

\begin{tabular}{|c|c|c|c|}
\hline & $\begin{array}{l}\mathrm{Pd}(\mathrm{OAc})_{2}(10 \mathrm{~mol} \%) \\
\mathrm{PPh} h_{3}(20 \text { mol \%) } \\
\mathrm{Nu}-\mathrm{H}(2.0 \text { equiv) } \\
\mathrm{Cs}_{2} \mathrm{CO}_{3}(1.2 \text { equiv }) \\
\text { xylene, } 130{ }^{\circ} \mathrm{C}\end{array}$ & :0a-j & $\prod_{\substack{\mathrm{N} \\
\mathrm{Bn}^{\prime}-\mathrm{Nu}}}$ \\
\hline entry & $\mathrm{Nu}-\mathrm{H}$ & time $(\mathrm{h})$ & yield $(\%)$ \\
\hline 1 & $p-\mathrm{NsNH}_{2}$ & 2 & 20a: $51^{[\mathrm{a}]}$ \\
\hline 2 & $p$-TsNH 2 & 0.5 & 20b: 73 \\
\hline 3 & $\mathrm{TfNH}_{2}$ & 3 & 20c: 94 \\
\hline 4 & morpholine & 1 & 20d: 0 \\
\hline 5 & aniline & 24 & 20e: 0 \\
\hline 6 & indole & 8 & 20f: 62 \\
\hline 7 & phenol & 0.5 & 20g: $81^{[b]}$ \\
\hline 8 & benzoic acid & 0.5 & 20h: 74 \\
\hline 9 & $\mathrm{PhB}(\mathrm{OH})_{2}$ & 0.5 & 20i: 58 \\
\hline 10 & $\mathrm{PhCH}=\mathrm{CHB}(\mathrm{OH})_{2}$ & 24 & $\mathbf{2 0 j}:>37$ \\
\hline
\end{tabular}

[a] A doubly alkylated product was obtained in $29 \%$ yield as a by-product. [b] A carbamate was obtained in $10 \%$ yield.

Following on from our successful synthesis of several 3,3-disubstituted oxindoles via the trapping of a $\pi$-allylpalladium intermediate with a range of nucleophiles, we proceeded to investigate the direct 
synthesis of spirooxindoles based on an extension of this approach. This extended approach involved sequential palladium(0)-catalyzed amidation and intramolecular nucleophilic addition reactions, which were conducted in a single pot (Scheme 4). Carbamoyl chloride 26 was prepared from aryl iodide 22 via a six-step linear sequence, including a Stille coupling with trimethylstannyl-1,3-hexadiene $\mathbf{2 3},{ }^{26}$ as well as the introduction of a nitrogen unit using $\mathrm{TfNH}_{2}$. The domino cyclization of $\mathbf{2 6}$ was conducted in the presence of $10 \mathrm{~mol} \% \mathrm{Pd}(\mathrm{OAc})_{2}, 20 \mathrm{~mol} \% \mathrm{PPh}_{3} 1.2$ equiv. of $\mathrm{Cs}_{2} \mathrm{CO}_{3}$ (1.2 equiv) at $130{ }^{\circ} \mathrm{C}$, and gave the desired spirocyclic products $27 \mathbf{a}$ and $\mathbf{2 7} \mathbf{b}$ in a combined yield of $71 \%$ as a $63: 37$ mixture of two diastereomers. The newly generated stereochemistry was determined by extensive 2D NMR measurements, including NOE experiments. Notably, the major product 27a possessed the same configuration as spirotryprostatin A (4) and elacomine (7) (Figure 1).

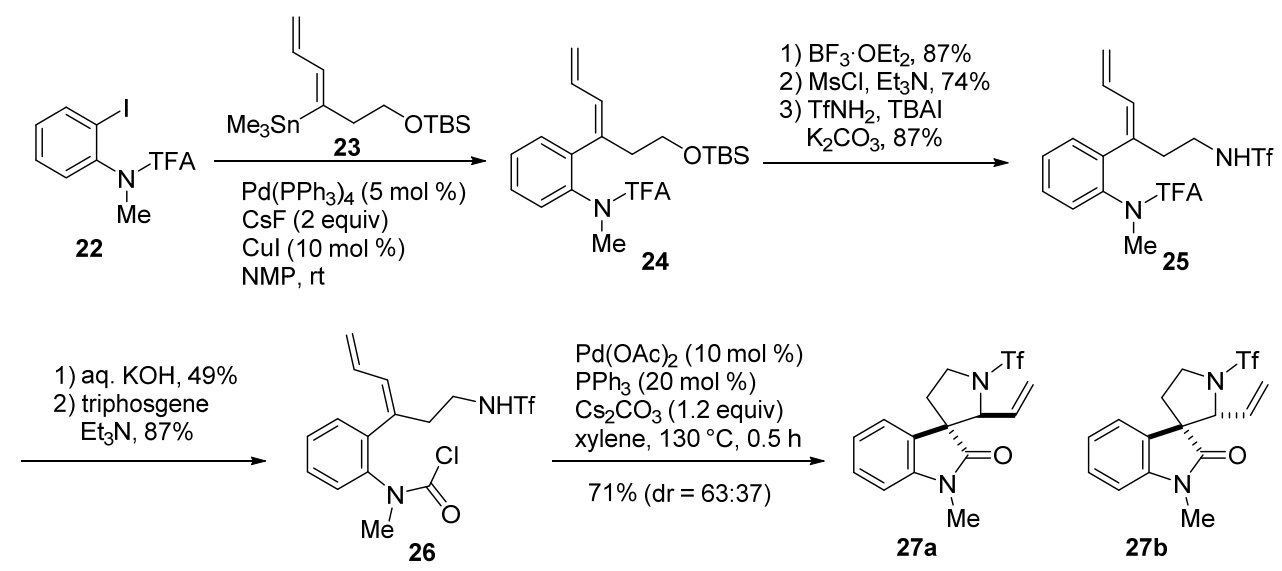

Scheme 4. Application of the palladium(0)-catalyzed amidination for spiro-ring formation

A novel domino palladium-catalyzed method was developed by our group for the direct synthesis of spirooxindole 27 from carbamoyl chloride 26 bearing a terminal 1,3-diene moiety. ${ }^{20}$ Although the selectivity of the spiro-ring formation was poor, we proceeded to investigate the application of this palladium-catalyzed spirooxindole formation to the formal synthesis of elacomine (7) and isoelacomine (8).

\section{1-4. FORMAL SYNTHESIS OF ELACOMINE BY THE DOMINO}

\section{PALLADIUM(0)-CATALYZED SPIROOXINDOLE FORMATION}

Elacomine (7, Figure 1) is a hemiterpene spirooxindole alkaloid, which was first isolated from the shrub Elaeagnus commutata in 1968 by Slywka et al. ${ }^{\text {a }}$ The structure of elacomine was determined by X-ray crystallography by James and Williams. ${ }^{7 b}$ Borschberg et al. ${ }^{27}$ later reported that 7 occurred naturally in its racemic form following a series of re-isolation studies. The first enantioselective total synthesis of 7 and 
its diastereomer $\mathbf{8}$, which is known as isoelacomine and was isolated from the same species, was described by Borschberg in the same paper, and proceeded via the oxidative rearrangement of $\beta$-carboline. The authors of this particular study also reported that elacomine and isoelacomine could be interconverted and undergo racemization under mild conditions. Although compounds $\mathbf{7}$ and $\mathbf{8}$ have not been reported to exhibit any biological activity, these molecules are regarded by many researchers as important synthetic targets and benchmark compounds, because they contain a simple spiro(pyrrolidine-3,3-oxindole) skeleton that is often found in spirooxindole natural products. In 2004 , Horne et al. ${ }^{28}$ reported the total synthesis of $\mathbf{7}$ and $\mathbf{8}$ based on a stereoselective intramolecular iminium ion spirocyclization method. White et al. $^{29}$ developed a tandem intramolecular photocycloaddition retro-Mannich fragmentation strategy and applied it to the diastereoselective synthesis of 7. Notably, tryptamine derivatives were selected as starting materials in all three of these total syntheses, with the main focus of each approach being the construction of the spiro-center.

We envisioned that the application of our newly developed domino reaction to an internal 1,3-diene would allow for the efficient construction of the spirooxindole skeleton of elacomine (7) and isoelacomine (8) from carbamoyl chloride 29, which would act as a cyclization precursor (Scheme 5). Oxidative addition and insertion into the 1,3-diene would give the $\pi$-allylpalladium complexes 30a and 30b as well as the oxindole. Intramolecular nucleophilic attack to the $\pi$-allylpalladium moiety would give compound 28. Considering the acidity required to generate a suitably nucleophilic nitrogen-based nucleophile and the feasibility of the subsequent deprotection, a methoxy carbamate was chosen as an internal nitrogen-based nucleophile (i.e., $\mathrm{R}^{2}=\mathrm{Me}$ ). Carbamoyl chloride 29 could be synthesized in several steps, including the Heck reaction of iodoaniline $\mathbf{3 1}$ and dihydro- $2 H$-pyranone $\mathbf{3 2}$ followed by the ring-opening of the dihydro- $2 \mathrm{H}$-pyranone moiety to allow for the introduction of the nitrogen and isoprenyl units, and the formation of the carbamoyl chloride.

Practical work towards realizing this strategy was initially focused on the intermolecular Heck reaction of dihydro- $2 H$-pyranone 32, because the reaction of this species had not been reported in the same way as the intermolecular Heck reaction of cyclic enones. ${ }^{30}$ Screening experiments revealed that $\mathbf{3 1 a}$ could be coupled to 32 using $\mathrm{Pd}(\mathrm{OAc})_{2}, \mathrm{PPh}_{3}, i \mathrm{Pr}_{2} \mathrm{NEt}$ and tetrabutylammonium bromide $\left(\mathrm{Bu}_{4} \mathrm{NBr}\right)$ in dimethylformamide (DMF) at $100{ }^{\circ} \mathrm{C}$ followed by deprotection of the $t$-butoxycarbonyl (Boc) group to give lactone 33 in a $52 \%$ yield over the two steps (Scheme 6). The diene unit was introduced by the half-reduction of lactone 33 using diisobutylaluminum hydride (DIBAL-H) followed by a Wittig reaction. Trifluoroacetylation of the aniline moiety followed by mesylation of the primary alcohol gave $\mathbf{3 5}$, which was treated with $\mathrm{NaN}_{3}$ to give the corresponding azide 36. Reduction of the azide followed by the protection of the resulting amine as a methoxy carbamate gave compound 37, which was treated with $\mathrm{KOH}$ to allow for the deprotection of the trifluoroacetyl group. The resulting secondary amine $\mathbf{3 8}$ was 
treated with a mixture of triphosgene and pyridine in $\mathrm{CH}_{2} \mathrm{Cl}_{2}$ at $-78{ }^{\circ} \mathrm{C}$ to give carbamoyl chloride 29a, which could be used as a cyclization precursor.

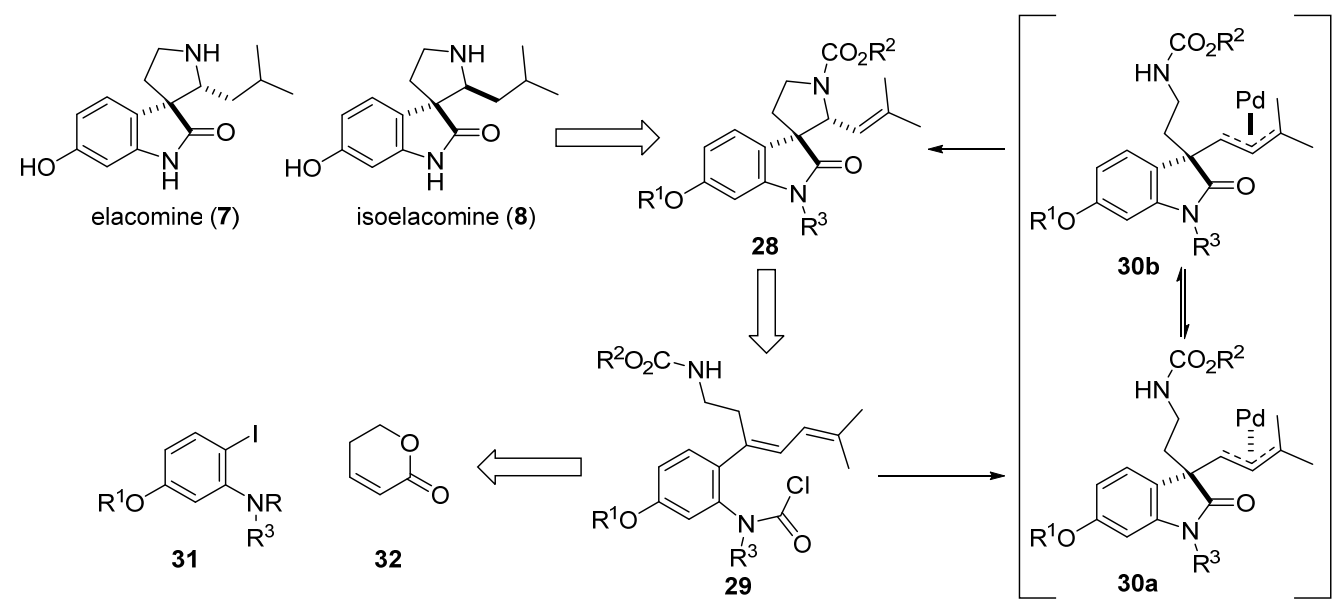

Scheme 5. Retrosynthetic analysis of elacomine (7) and isoelacomine (8)
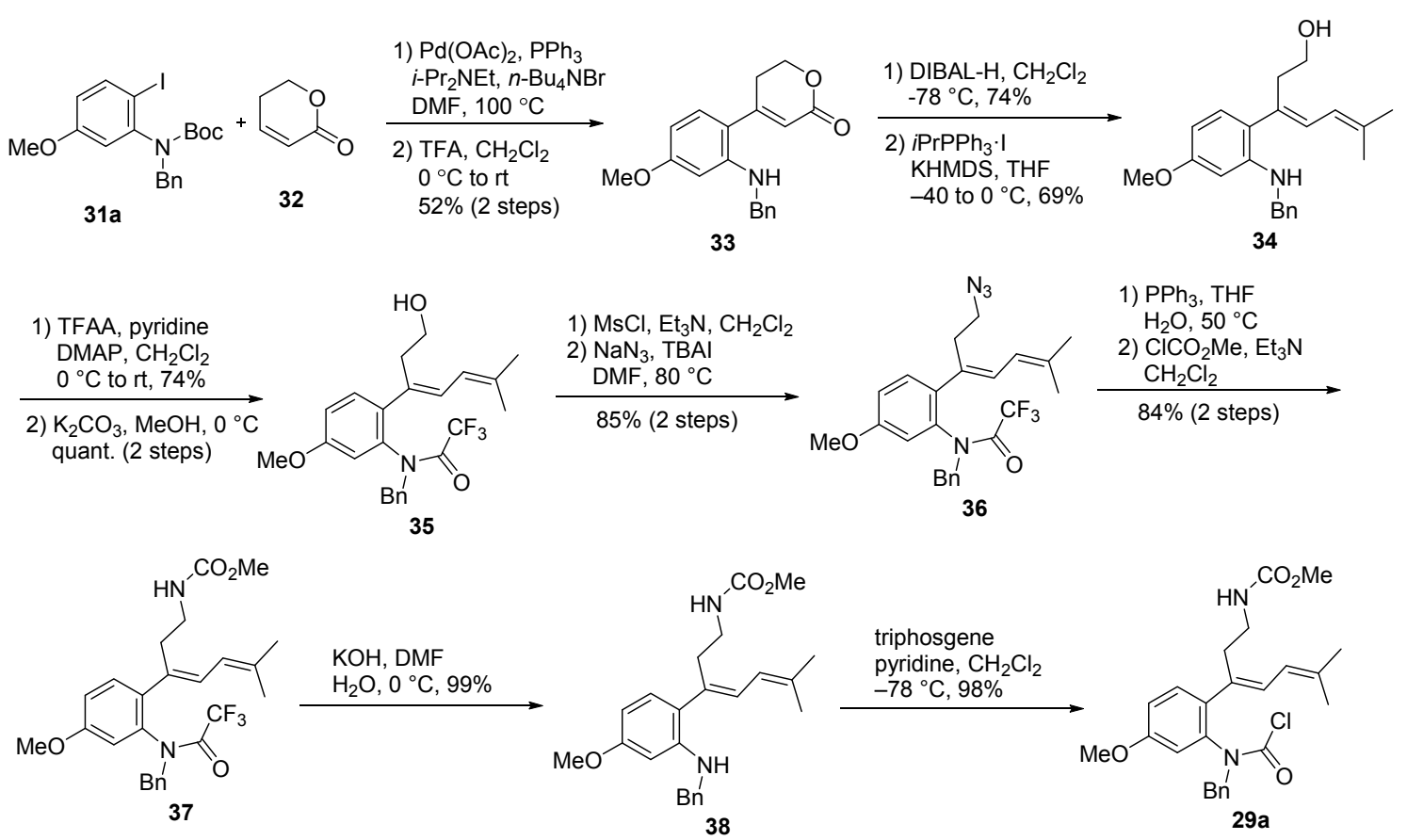

Scheme 6. Synthesis of carbamoyl chloride 29a

We subsequently investigated the domino palladium-catalyzed spirooxindole formation of carbamoyl chloride 29a bearing an internal diene moiety. Compound 29a was initially subjected to a set of conditions that had been optimized for terminal dienes, such as those shown in Scheme $4 .{ }^{20}$ Unfortunately, however, the treatment of 29a with $\mathrm{Pd}(\mathrm{OAc})_{2}, \mathrm{PPh}_{3}$ and $\mathrm{Cs}_{2} \mathrm{CO}_{3}$ in xylene at $130{ }^{\circ} \mathrm{C}$ gave compound 39 in a $86 \%$ yield, which was most likely produced by the $\beta$-elimination of the $\pi$-allylpalladium complex 
instead of the nucleophilic addition of the nitrogen atom (Table 2, entry 1). Several additives and ligands were screened in an attempt to suppress the undesired $\beta$-elimination. Disappointingly, the use of diphenylphosphinoferrocene (dppf) as a ligand or $\mathrm{Bu}_{4} \mathrm{NPF}_{6}$ as an additive in the presence of $\mathrm{Cs}_{2} \mathrm{CO}_{3}$ or $\mathrm{Ag}_{2} \mathrm{CO}_{3}$ proved to be unsuccessful, whereas the addition of $\mathrm{Bu}_{4} \mathrm{NI}$ led to the formation of 28 in only $11 \%$ yield with no diastereoselectivity (Table 2, entries 2-5). Interestingly, the reaction proceeded smoothly to give the desired spirooxindole $\mathbf{2 8}$ as the major product when it was conducted without a base such as $\mathrm{Cs}_{2} \mathrm{CO}_{3}$ (Table 2, entry 6). Given that the undesired $\beta$-elimination step could potentially be suppressed under acidic conditions, we investigated the addition of several acids to the reaction mixture, including $\mathrm{TfOH}, \mathrm{Hf}(\mathrm{OTf})_{4}$ and $\mathrm{Bi}(\mathrm{OTf})_{3}$ (Table 2, entries 7-9). The results of these experiments revealed that $\mathrm{Bi}(\mathrm{OTf})_{3}$ was an effective additive for this domino palladium-catalyzed spirooxindole formation (Table 2, entry 9). The resulting spirooxindole $\mathbf{2 8}$ was isolated as a 1:1 mixture of diastereomers in all cases because the inversion of the $\pi$-allylpalladium intermediates 30a and 30b would occur prior to the nucleophilic addition of the nitrogen atom (Scheme 5).

Table 2. Palladium-catalyzed spirooxindole formation of carbamoyl chloride 29a

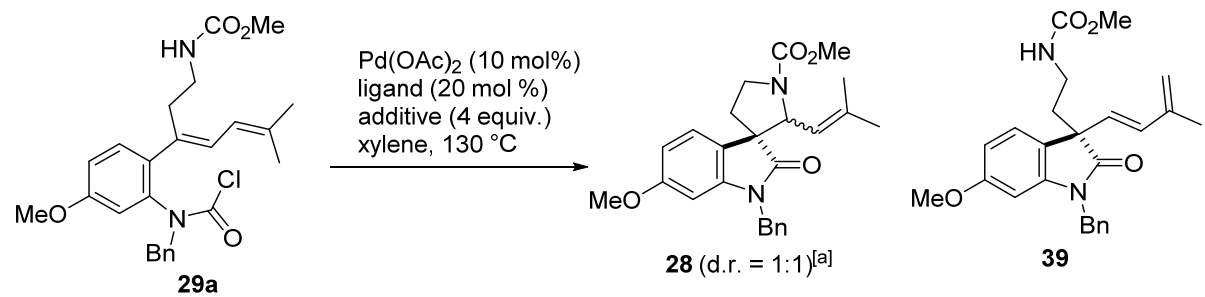

\begin{tabular}{|c|c|c|c|c|}
\hline entry & ligand & additives & yield $(\%)$ of $\mathbf{2 8}$ & yield $(\%)$ of $\mathbf{3 9}$ \\
\hline 1 & $\mathrm{PPh}_{3}$ & $\mathrm{Cs}_{2} \mathrm{CO}_{3}$ & 0 & 86 \\
\hline 2 & $\mathrm{PPh}_{3}$ & $\mathrm{Cs}_{2} \mathrm{CO}_{3}, \mathrm{Bu}_{4} \mathrm{NPF}_{6}$ & 0 & 66 \\
\hline 3 & $\mathrm{PPh}_{3}$ & $\mathrm{Cs}_{2} \mathrm{CO}_{3}, \mathrm{Bu}_{4} \mathrm{NI}$ & 11 & 28 \\
\hline 4 & Dppf & $\mathrm{Cs}_{2} \mathrm{CO}_{3}$ & 0 & 84 \\
\hline 5 & Dppf & $\mathrm{Ag}_{2} \mathrm{CO}_{3}$ & 0 & 74 \\
\hline 6 & $\operatorname{Dppf}^{[\mathrm{b}]}$ & none & 37 & 17 \\
\hline 7 & Dppf & $\mathrm{TfOH}^{[\mathrm{c}]}$ & 17 & 0 \\
\hline 8 & Dppf & $\mathrm{Hf}(\mathrm{OTf})_{4}$ & 33 & 0 \\
\hline 9 & Dppf & $\mathrm{Bi}(\mathrm{OTf})_{3}$ & 52 & 0 \\
\hline
\end{tabular}

[a] The ratio was estimated by ${ }^{1} \mathrm{H}$ NMR. [b] $\mathrm{Pd}(\mathrm{TFA})_{2}$ was used instead of $\mathrm{Pd}(\mathrm{OAc})_{2}$. [c] $50 \mathrm{~mol} \%$ was used.

The Lewis acid catalyzed intramolecular hydroamination of $\mathbf{3 9}$ was investigated to determine whether diene 39 was formed as an intermediate in the domino cyclization reaction described above. The 
treatment of 39 with a $\mathrm{Bi}(\mathrm{OTf})_{3}$ or $\mathrm{Hf}(\mathrm{OTf})_{4}$ catalyst in xylene at $130{ }^{\circ} \mathrm{C}$ according to the conditions described above for the domino cyclization reaction, except for the absence of the palladium catalyst and ligand, gave spirooxindole 28 as a mixture of diastereomers in 49 and $41 \%$ yields, respectively (Table 3, entries 1 and 2). The use of Shibasaki's conditions, ${ }^{31}$ which involved the use of a $\mathrm{PF}_{6}$ salt and $\mathrm{Bi}(\mathrm{OTf})_{3}$, $\mathrm{Hf}(\mathrm{OTf})_{4}$ or $\mathrm{Sc}(\mathrm{OTf})_{3}$, led significant improvements in the yield, with a combination of $\mathrm{Bi}(\mathrm{OTf})_{3}$ and $\mathrm{KPF}_{6}$ being especially effective (Table 3 , entries $\left.3-6\right){ }^{32}$ In contrast, the use of $\mathrm{Zn}(\mathrm{OTf})_{2}$ did not afford any of the cyclized products (Table 3, entry 7). The diastereoselectivity of the cyclization was found to be 1:3 under almost all of the conditions tested, and therefore different to the results observed in the domino cyclization process. These results therefore indicated that $\mathbf{3 9}$ was not an intermediate in the domino cyclization reaction. A comparison of these results with those from the hydroamination reaction suggested that nucleophilic addition to the $\pi$-allylpalladium complex would be preferred to the hydroamination pathway in the domino reaction.

Table 3. Hydroamination of diene 39

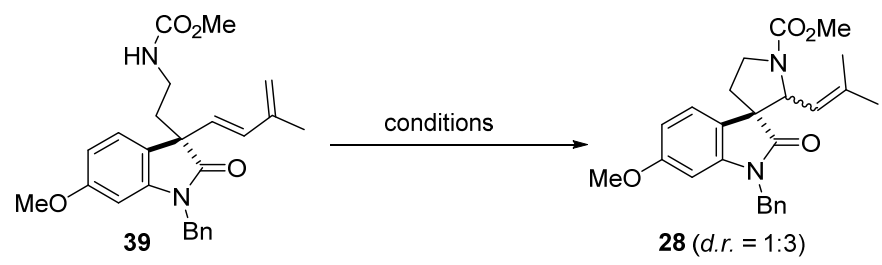

\begin{tabular}{ccccc}
\hline entry & conditions & solvent & temp $\left({ }^{\circ} \mathrm{C}\right)$ & yield $(\%)$ \\
\hline 1 & $\mathrm{Bi}(\mathrm{OTf})_{3}$ & xylene & 130 & 49 \\
2 & $\mathrm{Hf}(\mathrm{OTf})_{4}$ & xylene & 130 & $41^{\text {[a] }}$ \\
3 & $\mathrm{Bi}(\mathrm{OTf})_{3}, \mathrm{Cu}\left(\mathrm{MeCN}_{4} \mathrm{PF}_{6}\right.$ & 1,4-dioxane & 50 & 66 \\
4 & $\mathrm{Bi}(\mathrm{OTf})_{3}, \mathrm{KPF}_{6}$ & 1,4-dioxane & 50 & 80 \\
5 & $\mathrm{Hf}(\mathrm{OTf})_{4}, \mathrm{KPF}_{6}$ & 1,4-dioxane & 50 & 57 \\
6 & $\mathrm{Sc}(\mathrm{OTf})_{3}, \mathrm{KPF}_{6}$ & 1,4-dioxane & 50 & 58 \\
7 & $\mathrm{Zn}(\mathrm{OTf})_{2}, \mathrm{KPF}_{6}$ & 1,4-dioxane & 50 & 0 \\
\hline
\end{tabular}

[a] mixture of 1:2 diastereomers.

Having successfully synthesized spirooxindole 28, which possessed the same carbon skeleton as elacomine (7) and isoelacomine (8), we turned our attention to the final stage of the synthesis. The hydrogenation of $\mathbf{2 8}$ under high pressure conditions gave diastereomers $\mathbf{4 0 a}$ and 40b, which were separated by column chromatography over silica gel (Scheme 7). Finally, the formal synthesis of elacomine and isoelacomine was achieved by the removal of the benzyl group from the nitrogen atom of 
the isoxazole ring with lithium di-t-butylbiphenyl (LiDBB). The spectral data for the key intermediates 41a and 41b were in agreement with those reported by Horne et al. ${ }^{28}$

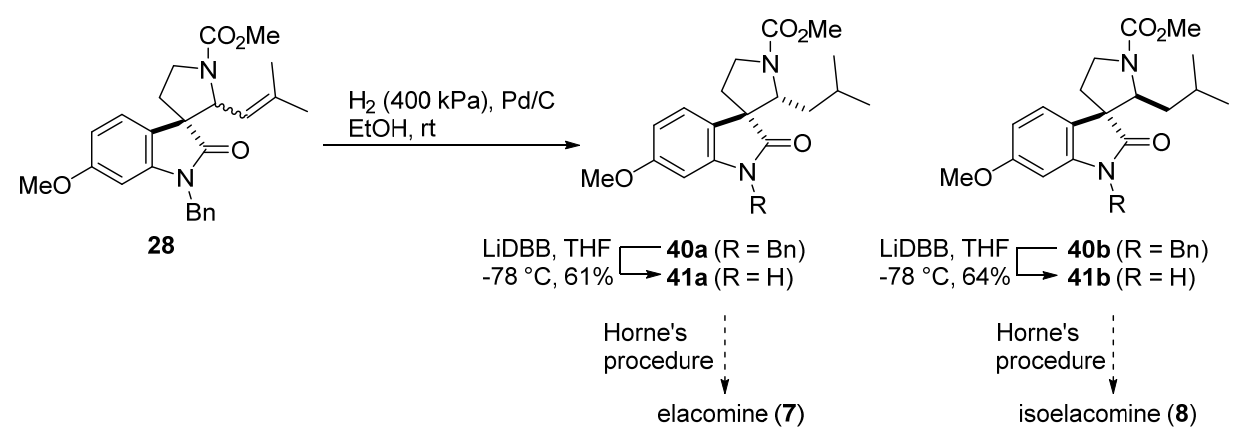

Scheme 7. Formal synthesis of elacomine (7) and isoelacomine (8)

This newly developed domino palladium-catalyzed spirooxindole formation was successfully applied to the formal synthesis of elacomine (7) and isoelacomine (8). It is noteworthy that terminal and internal dienes could both be employed in this domino cyclization. ${ }^{21}$

\section{1-5. SYNTHESIS OF SPIROOXINDOLES USING SILYL AMIDATION}

The focus of our research subsequently shifted to synthesizing spirooxindoles fused with tetrahydropyran, piperidine, and five-membered carbocycle ring systems. Developing a unified synthetic strategy capable of providing access to various spirooxindoles would be of considerable value to synthetic and medicinal chemists because it could be applied to the synthesis of natural products as well as compound libraries for use in drug discovery. The domino cyclization reaction described above ${ }^{20,21}$ is a convenient method for constructing spiro-ring systems fused with pyrrolidine, although the scope of this reaction has been limited by its requirement for strong nucleophiles to allow for the intramolecular trapping of the $\pi$-allylpalladium intermediate. For this reason, the domino cyclization reaction could be unsuitable for the synthesis of other spiro-ring systems. To develop a comprehensive method capable of providing access to various spirooxindole systems, we turned our attention to the bismetallation of 1,3-dienes, which provides products containing two carbon-metal bonds that could be subjected to further transformations. ${ }^{33}$ Mori et al. $^{34}$ developed a nickel-catalyzed process for the bismetallative cyclization of 1,3-dienes with an aldehyde on their side chain. Furthermore, the same reaction with $\mathrm{Me}_{3} \mathrm{SiSnBu}_{3}$ gave a cyclized product containing an allylstannyl group. This reaction was extended to include the formation of two carbon-carbon bonds by sequential allylic transfer reactions in one pot by $\mathrm{Yu}^{35}$ The nickel-catalyzed cyclization of 1,3-dienes with internal and external aldehydes in the presence of a diboronyl reagent proceeded in high levels of diastereoselectivity. Based on this bismetallative cyclization process, we 
became interested in developing a carbosilylation strategy for constructing various spirooxindole ring systems. We envisioned that the treatment of 1,3-diene $\mathbf{1 3}$ bearing a carbamoyl chloride with a catalytic amount of palladium catalyst and hexamethyldisilane would give the disubstituted oxindole 42 via the reaction of the $\pi$-allyl complex 41 with the internal carbamoyl chloride (Scheme 8). The C1 position of the diene unit would be converted to a quaternary carbon center and the resulting oxindole $\mathbf{4 2}$, bearing an allylic silanyl group, could be readily converted to spirooxindole $\mathbf{4 3}$ by the Sakurai-type reaction of the tethered electrophile (R"), which would allow for a high level of control over the three contiguous stereocenters. Although the realization of this strategy would mean that the spirooxindole ring would have to be formed in a stepwise manner, various spiro-ring systems could be accessed from this intermediate by the nucleophilic attack of the allyl metal species on the electrophile in the side chain. Conceptually, this idea is effectively the reverse of that described above for the domino cyclization reaction in terms of the nucleo- and electro-philicity of the allyl metal intermediate derived from the diene.

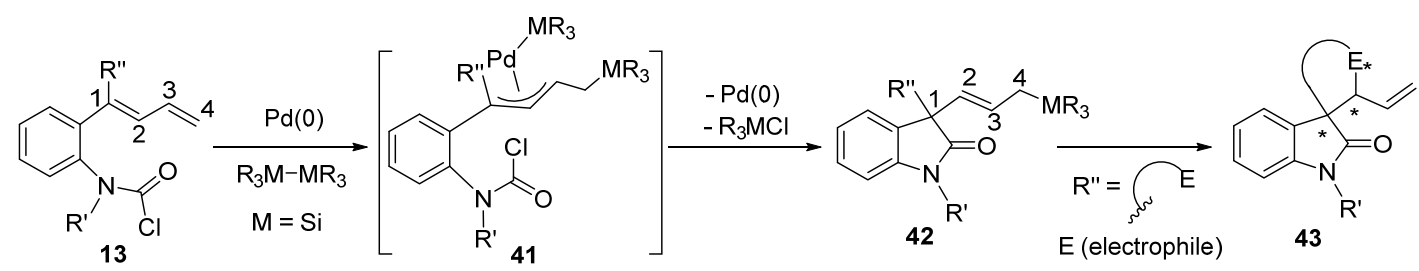

Scheme 8. Synthetic strategy for spirooxindole fused with various rings

When we started our work in this area, there had been no reports in the literature pertaining to the palladium-catalyzed bismetallative cyclization of a carbamoyl chloride with a 1,1-disubstituted diene. In the absence of any related examples to guide our research, our initial efforts focused on the carbosilylation of 1,3-diene 19 using hexamethyldisilane and $10 \mathrm{~mol} \%$ of a palladium or rhodium catalyst in xylene (Table 4). Although the use of $\mathrm{Rh}\left(\mathrm{PPh}_{3}\right)_{3} \mathrm{Cl}$ as a catalyst resulted in none of the desired cyclization product, the use of the chloro(1,5-cyclooctadiene)rhodium(I) dimer ([Rh(cod)Cl $\left.]_{2}\right)$ gave 44 in $43 \%$ yield as a mixture of $(E)$ - and $(Z)$-isomers (Table 4 , entries 1 and 2$).{ }^{36}$ Several palladium catalysts were screened against this reaction and performed effectively in the cyclization to give the desired product 44 in 22\%-75\% yields (Table 4, entries 3-7). ${ }^{37}$ Interestingly, however, the addition of $\mathrm{PPh}_{3}$ hampered the cyclization reaction (Table 4, entries 8 and 9). Finally, we found that the allylpalladium(II) chloride dimer $\left[\mathrm{Pd}\left(\eta^{3} \text {-allyl }\right) \mathrm{Cl}\right]_{2}$ was an efficient catalyst for this transformation, with $5 \mathrm{~mol} \%$ catalyst allowing the reaction to proceed to completion within $1 \mathrm{~h}$ to afford the desired product 44 in $77 \%$ yield (Table 4, entry 10). 
Table 4. Screening of palladium and rhodium catalysts for the carbosilylation reaction

\begin{tabular}{|c|c|c|c|c|}
\hline entry & catalyst & temp $\left({ }^{\circ} \mathrm{C}\right)$ & time $(\mathrm{h})$ & yield $(\%)$ \\
\hline 1 & {$[\mathrm{Rh}(\operatorname{cod}) \mathrm{Cl}]_{2}$} & 130 & 10 & $43^{[\mathrm{a}]}$ \\
\hline 2 & $\mathrm{Rh}\left(\mathrm{PPh}_{3}\right)_{3} \mathrm{Cl}$ & 130 & 24 & 0 \\
\hline 3 & $\operatorname{Pd}(\mathrm{TFA})_{2}$ & 100 & 24 & 22 \\
\hline 4 & $\operatorname{Pd}(\mathrm{acac})_{2}$ & 100 & 8 & 32 \\
\hline 5 & $\operatorname{Pd}(\mathrm{dba})_{2}$ & 100 & 24 & 75 \\
\hline 6 & $\mathrm{Pd}(\mathrm{OAc})_{2}$ & 100 & 24 & 55 \\
\hline 7 & $\mathrm{PdCl}_{2}(\mathrm{PhCN})_{2}$ & 100 & 24 & 48 \\
\hline 8 & $\mathrm{Pd}(\mathrm{OAc})_{2}, \mathrm{PPh}_{3}$ & 130 & 2 & $12^{[\mathrm{a}]}$ \\
\hline 9 & $\mathrm{PdCl}_{2}(\mathrm{PhCN})_{2}, \mathrm{PPh}_{3}$ & 130 & 24 & 0 \\
\hline 10 & {$\left[\operatorname{Pd}\left(\eta^{3} \text {-allyl }\right) \mathrm{Cl}\right]_{2}{ }^{[\mathrm{b}]}$} & 100 & 1 & 77 \\
\hline
\end{tabular}

[a] Mixture of isomers. [b] $5 \mathrm{~mol} \%$ catalyst was used.

The optimal conditions were subsequently applied to a variety of substrates to assess the scope of this reaction (Table 5). Carbamoyl chlorides 45a-c were prepared from Boc-protected 2-iodoaniline, because the presence of a siloxyethyl or aminoethyl group was essential for the formation of the spiro-ring. Compounds $45 \mathbf{a}-\mathbf{c}$ were subsequently converted to the desired oxindoles $46 \mathbf{a}-\mathbf{c}$ in $75 \%-95 \%$ yields using $5 \mathrm{~mol} \%\left[\mathrm{Pd}\left(\eta^{3} \text {-allyl }\right) \mathrm{Cl}\right]_{2}$ and hexamethyldisilane. The substrate scope of this reaction was also investigated using carbamoyl chlorides without a siloxyethyl or aminoethyl side chain (i.e., 45d-f). A p-methoxybenzyl (PMB) group was tolerated under the cyclization conditions, with the PMB substituted product 46d being isolated in good yield. Substrates bearing a chlorine or methoxy group on their aromatic ring also reacted smoothly to give oxindoles 46 e and $46 f$ in $86 \%$ and $80 \%$ yields, respectively. Spirooxindoles fused with a five-membered carbocycle were synthesized by a Sakurai-type reaction ${ }^{38}$ using the 3,3-disubstituted oxindole described above (Scheme 9). The removal of the $t$-butyldimethylsilyl (TBS) group from 46a under acidic conditions gave alcohol 47, which was converted to enol ether 48 following sequential oxidation and Wittig reactions. Enol ether 48, which existed as a 2:1 mixture of $E: Z$ isomers, was converted to spirooxindole 49 under acidic conditions in $89 \%$ yield as a 5:3 mixture of diastereomers. The formation of spirooxindoles fused with a six-membered piperidine ring was also achieved with excellent diastereoselectivity. The Mitsunobu reactions of compound $\mathbf{4 7}$ with succinimide and glutarimide gave the corresponding addition products, which were reduced with $\mathrm{NaBH}_{4}$ to give the 
cyclization precursors $\mathbf{5 0 a}$ and $\mathbf{5 0 b}$, respectively. Treatment of compounds $\mathbf{5 0 a}$ and $\mathbf{5 0 b}$ with $\mathrm{BF}_{3} \cdot \mathrm{OEt}_{2}$ gave compounds 51a and 51b in 95\% and 98\% yields, respectively, with excellent diastereoselectivity, and the newly generated stereochemistry was confirmed by 2D NMR analyses, including NOESY experiments. Notably, these products possessed the same relative configuration as the core structure of tabernoxidine (9) (Figure 1). ${ }^{8}$

Table 5. Scope of the cyclization reaction ${ }^{[\mathrm{a}]}$

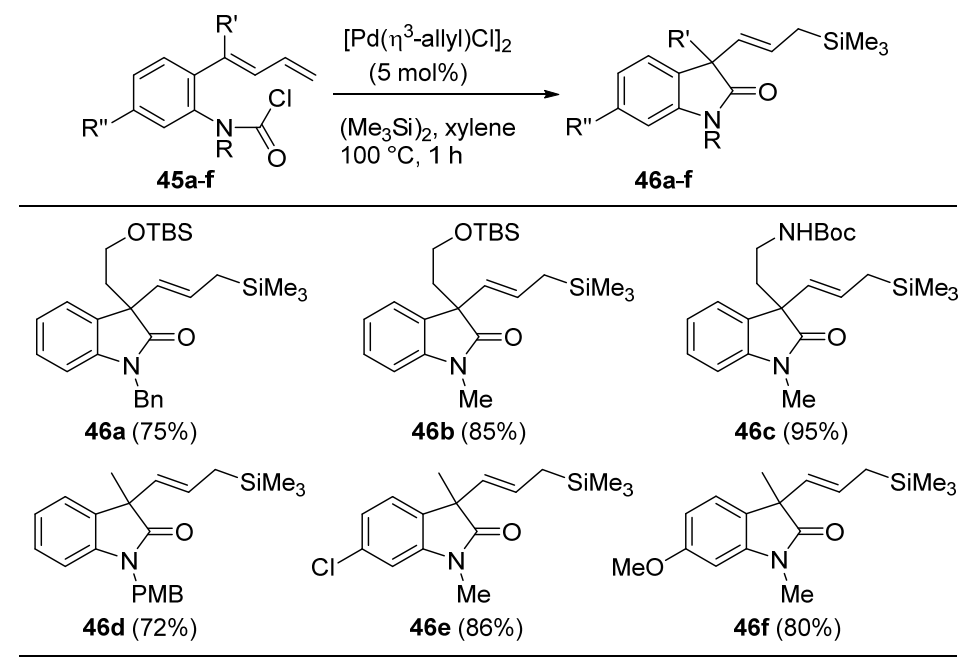

[a] TBS = tert-butyldimethylsilyl, Boc = tert-butoxycarbonyl
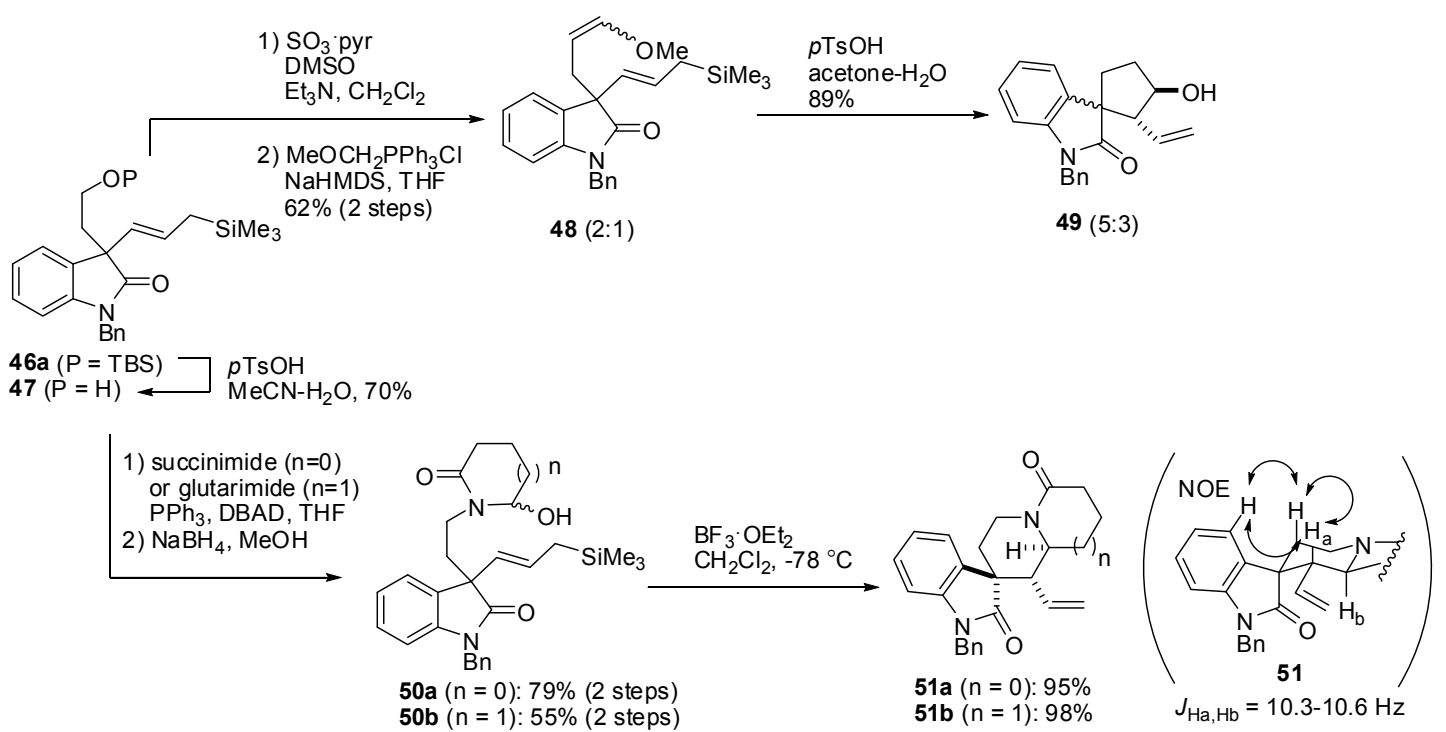

Scheme 9. Synthesis of spirooxindoles fused with piperidine and a five-membered carbocycle The 3,3-disubstitued oxindole 46c was used to synthesize a series of spirooxindoles fused with a tetrahydropyran ring using a Sakurai-type cyclization. Deprotection of the TBS group in compound 46c gave the corresponding alcohol 52, which was treated with trimethyl orthoformate or an aryl aldehyde in 
the presence of $\mathrm{BF}_{3} \cdot \mathrm{OEt}_{2}$ to give the spirooxindoles $\mathbf{5 3 a}-\mathbf{e}$ in high yields (Table 6). The reaction with trimethyl orthoformate gave 53a in $83 \%$ yield as a single diastereomer, and several other aldehydes, including electron-rich or electron-deficient aromatic aldehydes, reacted smoothly to give the desired products $\mathbf{5 3 b}-\mathbf{e}$ as single isomers in $78 \%-89 \%$ yields.

Table 6. Synthesis of spirooxindoles fused with tetrahydropyran

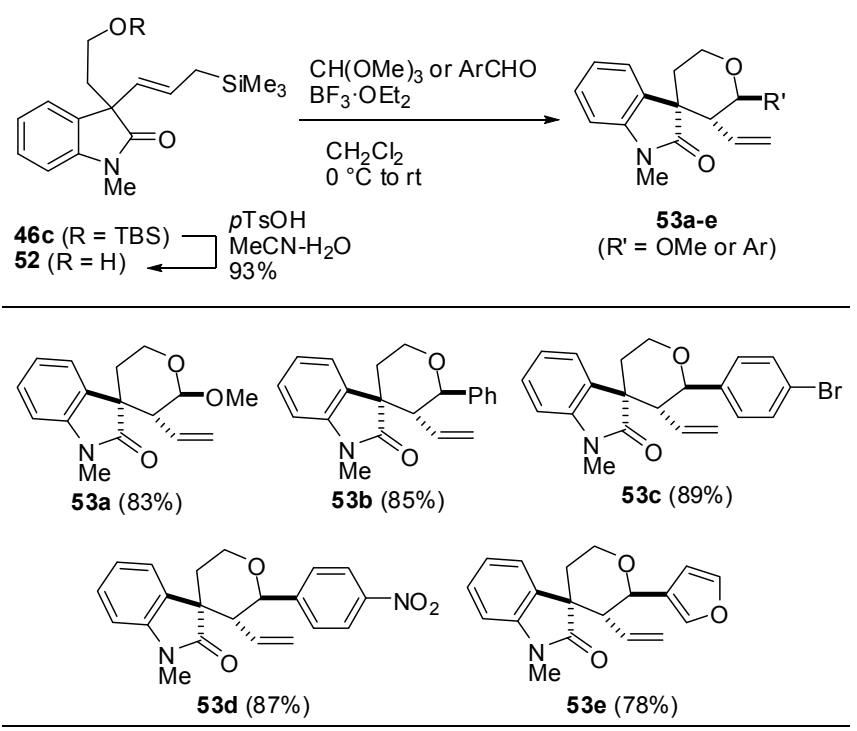

The excellent diastereoselectivity observed in this cyclization can be rationally explained as follows: It would be possible for the 3,3-disubstitued oxindole substrates to adopt four chair-like transition states A-D via the formation of an oxonium cation (Figure 2). Given that an aromatic ring is more sterically encumbered than an amide group, ${ }^{39}$ transition state $\mathbf{A}$, where the aromatic ring and allylic silane group are both sitting in pseudo-equatorial positions, would be energetically more favorable than transition states B-D.

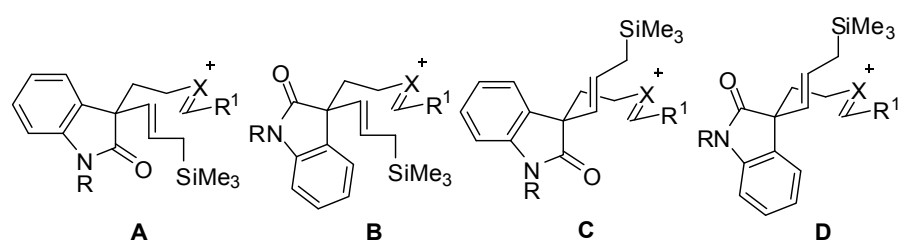

Figure 2. Transition states of Sakurai-type reaction $\left(X=\mathrm{NR}^{2}, \mathrm{O}\right)$

The examples shown above provide a good illustration of the powerful and concise nature of this newly developed method for constructing various spirooxindoles via the palladium-catalyzed carbosilylation of 1,3-dienes bearing a carbamoyl chloride moiety followed by a Sakurai-type cyclization. ${ }^{22}$ Spiro-ring systems fused with tetrahydropyran, piperidine, and five-membered carbocycles can be constructed according to this method with a high level of control over two or three contiguous stereocenters. 
Furthermore, the work described here was the first reported example of the construction of a quaternary stereocenter from the 1,1-disubstituted diene via a bismetallation strategy. ${ }^{40}$

Using this methodology, it is now possible to access spirooxindole systems fused with pyrrolidine, piperidine, five-membered carbocycle and six-membered lactone rings based on the originally developed method. These two synthetic strategies could therefore not only be useful for synthesizing natural spirooxindoles but could also be used to synthesize the intermediates of indole alkaloids.

\section{SYNTHETIC STUDIES ON 2-IMINOINDOLINE}

During the course of our synthetic studies of spirooxindoles, we became interested in synthesizing 2-iminoindolines (54a), 2-aminoindolenines (54b) and 2-aminoindolines (55) (Figure 3). In some cases, 54a and 54b could be tautomers of each other. The class of natural products containing these structures is very similar to that of spirooxindoles, and several interesting examples from this class have been reported in the literature, including communesin $\mathrm{F}(\mathbf{5 6}),{ }^{41}$ perophoramidine $(\mathbf{5 7}),{ }^{42}$ flustramine $\mathrm{C}(\mathbf{5 8}),{ }^{43}$ quinadoline $\mathrm{B}(\mathbf{5 9})^{44}$ and neoxaline $(\mathbf{6 0})^{45}$ (Figure 4). These compounds often exhibit interesting biological activities, and communesin F (56), perophoramidine (57) and neoxaline (60), for example, have been reported to be cytotoxic. Flustramine C (58) shows moderate antibiofilm activity against Acinetobacter baumannii, Escherichia coli and methicillin resistant Staphylococcus aureus (MRSA); ${ }^{46}$ and quinadoline B (59) has been reported as a moderate inhibitor of lipid droplet synthesis in mouse macrophages. The synthesis of these compounds, however, is challenging because of their complex structural architecture. In the latter half of this review, we will focus in detail on our synthetic efforts towards developing a robust strategy for constructing 2-iminoindolines. ${ }^{47,48}$
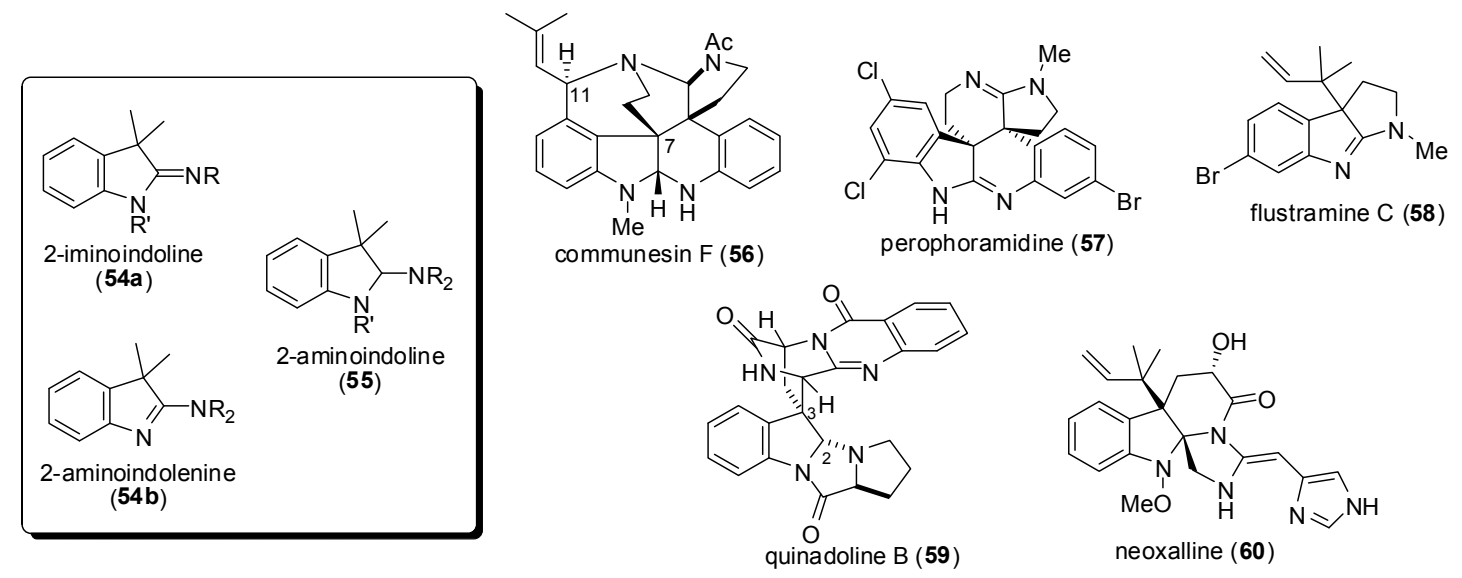

Figure. 3. Natural products containing 2-iminoindoline and 2-aminoindoles 


\section{2-1. REPORTED SYNTHETIC METHODS FOR CONSTRUCTING 2-IMINOINDOLINES AND RELATED COMPOUNDS}

Various methods have been reported in the literature for synthesizing 2-iminoindolines and related compounds. Most of the reported methods involve the tether-dependent condensation of oxindole derivatives ${ }^{49 a-d}$ and the oxidative cyclization of indoles. ${ }^{49}$ Several other synthetic strategies have also been developed to provide access to these systems, including aza-Pauson-Khand-type reactions, ${ }^{50}$ heteroannulation of $\mathrm{N}$-alkynylanilines, ${ }^{51}$ ring enlargement of aminoazirines, ${ }^{52}$ addition of azides to indoles, ${ }^{53}$ oxidation of aminals, ${ }^{54}$ and amidination of aryl halides. ${ }^{55}$ Despite several methods being available for constructing these compounds, the development of mild and selective synthetic methods is still highly desired.

\section{2-2. SmI $_{2}$-MEDIATED REDUCTIVE CYCLIZATION OF CARBODIIMIDES FOR SYNTHESIS OF SPIRO-2-IMINOINDOLINES}

For the synthesis of spiro-2-iminoindolines 61, we envisioned a retrosynthetic disconnection of the C2- $\mathrm{C} 3$ bond because we had already developed a synthetic method for constructing spirooxindoles by forming the $\mathrm{C} 2-\mathrm{C} 3$ bond (Scheme 10). Compound 62 bearing an unsaturated carbonyl group and a carbodiimide moiety was therefore identified as a suitable synthetic precursor for the cyclization reaction. Carbodiimides are often employed as synthetic precursors for amidines for their reactions with various organometallic species. ${ }^{56}$ However reports pertaining to their use as radical acceptors have been scarce. ${ }^{57}$

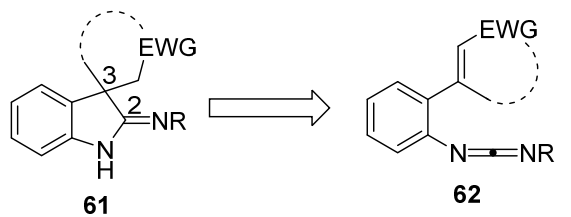

Scheme 10

$\mathrm{SmI}_{2}$, which was first introduced as a reagent for synthetic chemistry in 1977 by Kagan, is a powerful single-electron reductant. ${ }^{58,59} \mathrm{SmI}_{2}$ exhibits excellent functional group selectivity and is regularly used to affect the formation of carbon-carbon bonds and selective reduction reactions in synthesizing complex natural products. ${ }^{60}$ Although various reductive homo-/hetero-coupling reactions have been reported involving the reaction of $\mathrm{SmI}_{2}$ with substrates bearing electron-withdrawing groups, ${ }^{61}$ there have, to the best of our knowledge, been no reports to date pertaining to the development of similar reactions involving carbodiimides. ${ }^{62}$ 
Before we started this project, a report appeared in the literature describing the synthesis of oxindoles based on the $\mathrm{SmI}_{2}$-promoted intramolecular cyclization of aryl isocyanates bearing a cyclohexenone moiety as part of a synthetic study towards welwitindolinone A isonitrile. ${ }^{61 \mathrm{~g}}$ Inspired by these results, it was envisioned that a quaternary-carbon center and an imine carbon bond could be constructed via a reductive cyclization reaction involving $\mathrm{SmI}_{2}$, an $\alpha, \beta$-unsaturated carbonyl moiety and carbodiimide. According to this strategy, the radical or anionic species generated from the reaction of $\mathrm{SmI}_{2}$ with an unsaturated carbonyl group would attack the central carbon atom of the carbodiimide species, or vice versa. Although tandem nucleophilic addition and $6 \pi$ electrocyclic reactions have been reported for the related carbodiimides 62, which gave the corresponding dihydroquinazolines 63 and 2-aminoquinoline 64 , respectively, ${ }^{63,64}$ there have been no reports concerning similar cyclization reactions for $\mathbf{6 2}$ to give quaternary-carbon centers (Scheme 11).

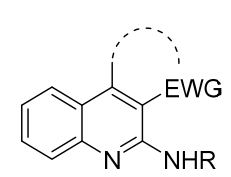

63

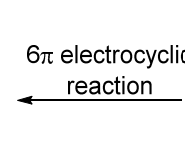

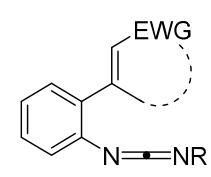

62

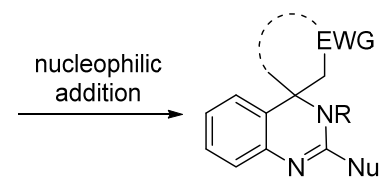

64

Scheme 11. Nucleophilic addition and $6 \pi$ electrocyclic reaction of the related carbodiimides 62

Compound 65 was selected as a simple model substrate to establish suitable conditions for the reductive cyclization reaction. Treatment of THF solution of $\mathbf{6 5}$ with $\mathrm{SmI}_{2}$ at $-78{ }^{\circ} \mathrm{C}$ resulted in no reaction (Table 7, entry 1), although the desired reaction did proceed at room temperature to give the cyclized product $\mathbf{6 6}$ exclusively (Table 7, entry 2). The addition of an additive to the reaction was also investigated, with hexamethylphosphoramide (HMPA) ${ }^{65}$ and $t$-butanol $\left({ }^{t} \mathrm{BuOH}\right)$ providing similar enhancements in the yield of the cyclized product (Table 7, entries 3 and 4). In contrast, the addition of several other additives, including $\mathrm{LiCl}^{66 \mathrm{a}}$ and $\mathrm{NiI}_{2}{ }^{66 \mathrm{~b}}$ did not lead to any significant improvements in the yield (Table 7, entries 5 and 6). The structure of iminoindoline 66 was unambiguously determined by the X-ray crystallographic analysis of 67, which was prepared by the Boc protection of 66 (Figure 4).

The scope and limitations of this $\mathrm{SmI}_{2}$-mediated reductive cyclization reaction were evaluated using a series of carbodiimides, and the results are shown in Table 8. Some of the cyclized products were found to be unstable, and the cyclization yields were therefore determined following the regioselective Boc protection of amidine. Under the optimal reaction conditions (method A), both electron-donating and electron-withdrawing functionalities were well tolerated on the phenyl ring to the left-hand side of the carbodiimide, including chlorine, methyl and methoxy groups, which gave the spirocyclic products 69a-d 
in $62 \%$ to $87 \%$ yields. It is noteworthy that compound $\mathbf{6 8 a}$, bearing a conformationally restricting substituent at the 3-position of its aromatic ring, reacted smoothly to give the desired product in good yield. When substrates $68 \mathbf{e}-\mathbf{i}$ bearing substituents on the phenyl ring to the right-hand side of the carbodiimides were used in the reaction, the optimized conditions (method A) gave lower yields of the cyclized products as well as several unidentified byproducts. Further experimental work concerning substrates $68 \mathrm{e}-\mathbf{i}$ revealed that the use of an inverse addition and changes to the amounts of $\mathrm{SmI}_{2}$ and $t$-butanol to the reaction (Table 8 , condition B) led to much higher yields with fewer byproducts. In the case of 68e, a small amount of byproduct was formed from a $6 \pi$ electrocyclic reaction, which most likely occurred as a result of Lewis acid-promoted acceleration through a chelated Sm species.

Table 7. Optimization of reaction conditions ${ }^{[\mathrm{a}]}$

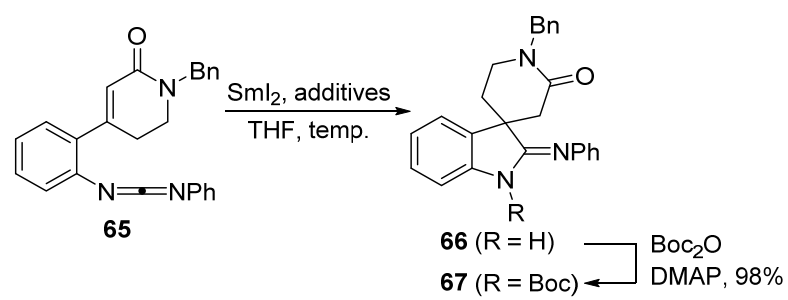

\begin{tabular}{cccc}
\hline entry & temp. & additives & yield (\%) of 66 \\
\hline 1 & $-78{ }^{\circ} \mathrm{C}$ & none & N.R. \\
2 & $\mathrm{rt}$ & none & 55 \\
3 & $\mathrm{rt}$ & $\mathrm{HMPA}^{[\mathrm{b}]}$ & 78 \\
4 & $\mathrm{rt}$ & ${ }^{t} \mathrm{BuOH}^{[\mathrm{c}]}$ & 83 \\
5 & $\mathrm{rt}$ & ${ }^{t} \mathrm{BuOH}^{c}+\mathrm{LiCl}^{[\mathrm{d}]}$ & 68 \\
6 & $\mathrm{rt}$ & ${ }^{t} \mathrm{BuOH}^{c}+\mathrm{NiI}_{2}{ }^{[\mathrm{e}]}$ & 79 \\
\hline
\end{tabular}

[a] Substrate solutions were added to $0.1 \mathrm{M} \mathrm{SmI}_{2}$ solutions (2.4 equiv.). [b] 10\% vol in $\mathrm{SmI}_{2}$ solution. [c] 2.2 equiv. [d] 10 equiv. [e] $5 \mathrm{~mol} \%$.

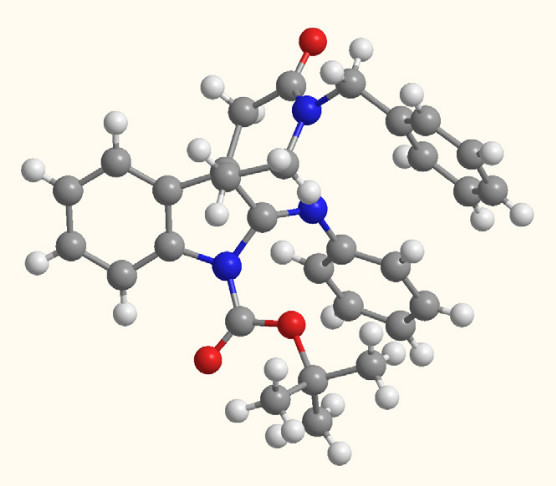

Figure 4. X-Ray structure of 67 
When the acyclic unsaturated ester $\mathbf{6 8} \mathbf{j}$ and lactone $\mathbf{6 8 \mathbf { k }}$ were subjected to the optimal reaction conditions (condition B) they gave the desired products $69 \mathbf{j}$ and $69 \mathrm{k}$ in $76 \%$ and $83 \%$ yields, respectively (Table 8 ). In sharp contrast, the reaction of the corresponding ethyl cinnamate $\mathbf{6 8 1}$ resulted in a complex mixture. Analysis of this mixture by mass spectroscopy revealed the presence of dimerized and trimerized products. These results therefore indicated that the $\beta, \beta$-disubstituted carbonyl moiety was essential to the success of the reaction.

Table 8. Scope and limitations of the reductive cyclization ${ }^{[\mathrm{a}]}$

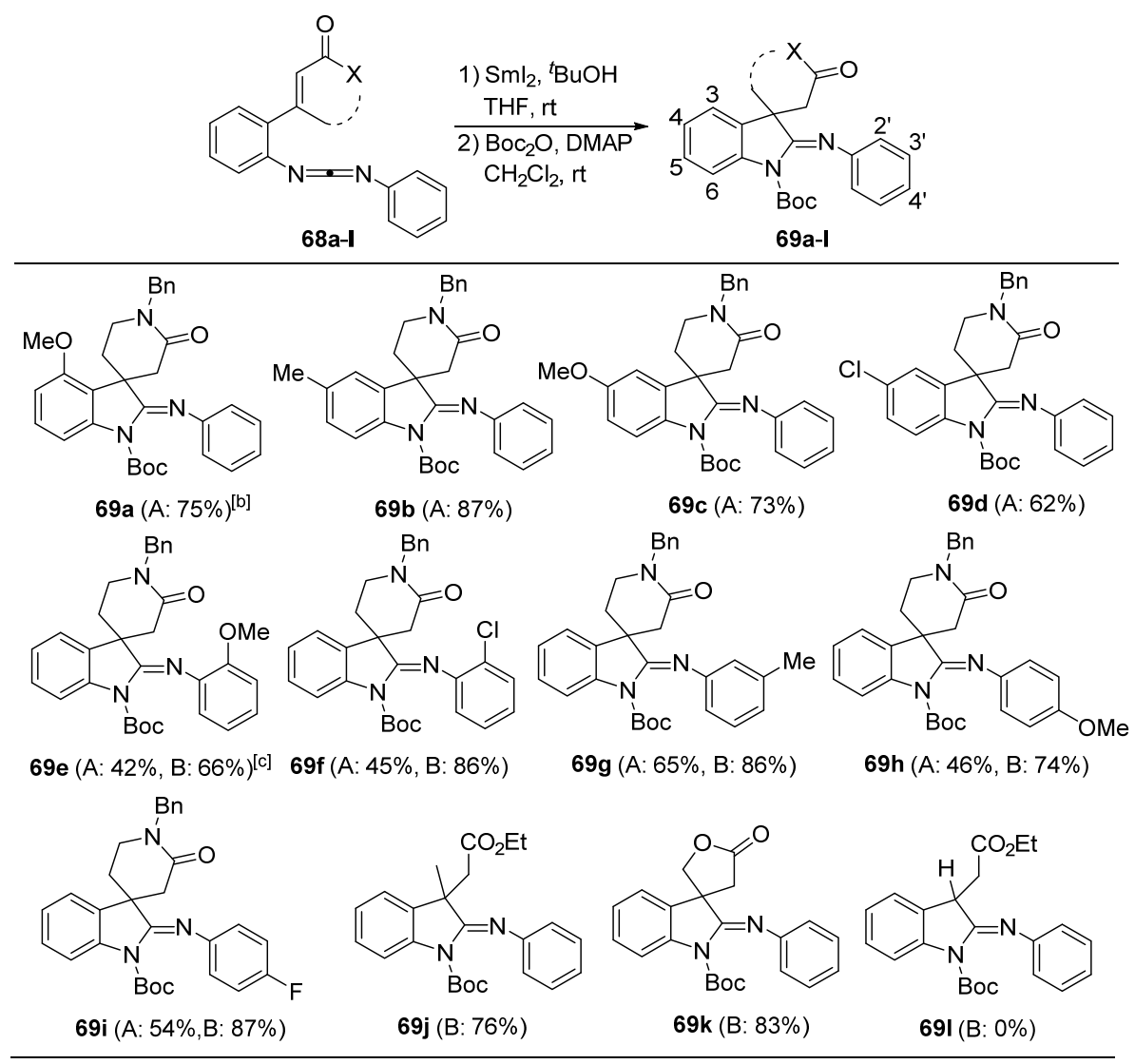

[a] All of these reactions were carried out on a $0.100 \mathrm{mmol} \mathrm{scale.} \mathrm{[b]} \mathrm{A} \mathrm{indicates} \mathrm{the} \mathrm{yield} \mathrm{from} \mathrm{condition}$ A: A THF solution of the substrate and ${ }^{t} \mathrm{BuOH}$ (2.2 equiv.) was added to a THF solution of $\mathrm{SmI}_{2}(2.4$ equiv.). [c] B indicates the yield from condition B: A THF solution of $\mathrm{SmI}_{2}$ (2.1-2.2 equiv.) was added to a THF solution of substrate and ${ }^{t} \mathrm{BuOH}$ (10 equiv.).

A possible mechanism for this reductive cyclization reaction is shown in Scheme 12. The carbonyl oxygen of compound $\mathbf{6 8}$ would initially coordinate to $\mathrm{SmI}_{2}$. The subsequent reduction of the unsaturated carbonyl group would produce a radical anion $\mathbf{7 0}$ that would attack the carbon of the carbodiimide at a faster rate than the samarium enolate. Further reduction by a second equiv. of $\mathrm{SmI}_{2}$ would provide the $\mathrm{Sm}$ amidinate 71. Given that cyclized product was formed in the absence of $t$-butanol, dianion $\mathbf{7 1}$ would be 
generated without the assistance of a proton source (Table 7, entry 2). Finally, protonation of 71 would give the reductively cyclized iminoindoline 69. However, it remains unclear whether the formation of the carbon-carbon bond is promoted by chelation between a carbodiimide moiety and $\mathrm{SmI}_{2}$ prior to the cyclization. The reported instability and difficulties associated with the generation of nitrogen-centered radical species ${ }^{57}$ suggest that dianion $\mathbf{7 1}$ could be formed from a chelated complex.

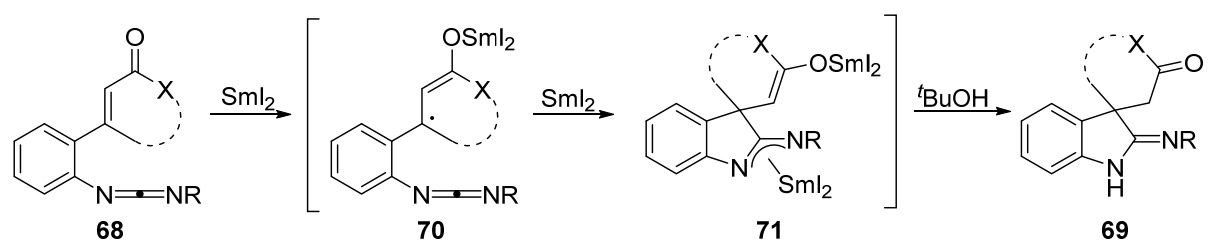

Scheme 12. Possible mechanism for the $\mathrm{SmI}_{2}$-promoted intramolecular reductive cyclization of carbodiimides

The $\mathrm{SmI}_{2}$-promoted intramolecular reductive cyclization reaction of carbodiimides bearing unsaturated carbonyl moieties was developed for the synthesis 2-iminoindolines bearing quaternary-carbon centers at their C3 position. ${ }^{47}$ We considered this newly developed synthetic method is a powerful tool for the construction of 2-iminoindolines, and consequently applied this strategy to synthesize the core structure of perophoramidine (57).

\section{2-3. SYNTHETIC STUDIES OF PEROPHORAMIDINE}

Perophoramidine (57) was isolated from an extract of Philippine ascidian Perophora namei by Ireland et al. $^{42}$ in 2002 (Figure 3). The structure of this compound is characterized by a pentacyclic alkaloid bearing two contiguous quaternary carbon stereocenters, and was determined following extensive spectroscopic analyses, including a series of 2D NMR experiments. Perophoramidine (57) has been reported to induce apoptosis via PARP cleavage as well as being cytotoxic towards HCT116 colon carcinoma cells, with an $\mathrm{IC}_{50}$ of $60 \mu \mathrm{M}$. Significant research efforts have been directed towards the synthesis of this natural product because of its highly complex polycyclic structure and interesting biological activities. ${ }^{67-75}$ In 2004, Funk et al. ${ }^{67 a}$ accomplished the first total synthesis of $( \pm)$-perophoramidine, and its absolute configuration was confirmed by Qin in 2010 following his total synthesis of $(+)$-perophoramidine. ${ }^{68 a}$ The key step in all of these syntheses was the Diels-Alder reaction of an indole with an ortho-quinone methide imine, which was inspired by the proposed biosynthetic pathway. ${ }^{69 a}$ Rainier also described a synthesis of $\left( \pm\right.$ )-dehaloperophoramidine $\mathbf{7 2},{ }^{71}$ and Wang recently reported the total synthesis of (+)-perophoramidine, which involved the catalytic asymmetric alkylation reaction of a 3-bromooxindole 
as a key step. ${ }^{75}$ We also became interested in the total synthesis of perophoramidine because we had developed a synthetic method for constructing 2-iminoindolines.

Dehaloperophoramidine $\mathbf{7 2}$ was selected as our initial target, because this compound can be synthesized from the pentacyclic compound 73 according to an existing procedure (Scheme 13). ${ }^{71}$ The key features of our retrosynthesis can be summarized as follows: (i) palladium-catalyzed intramolecular $\mathrm{C}-\mathrm{N}$ bond formation between the amidine nitrogen and the aryl chloride in spiro-2-iminoindoline 74; and (ii) the $\mathrm{SmI}_{2}$-mediated reductive cyclization of carbodiimide $\mathbf{7 5}$ bearing an electron-deficient tetrasubstituted olefin. This strategy was reliant on the aryl chloride moiety of $\mathbf{7 5}$ remaining intact throughout the $\mathrm{SmI}_{2}$-mediated reductive cyclization reaction so that it could then be used in the palladium-catalyzed cyclization. Our strategy for this compound was unique in terms of the way in which we planned to assemble the 3,3-disubstituted 2-iminoindoline during the initial stage of the process. In contrast, Funk, Qin, Rainier, and Wang had all employed indoles and their oxidized intermediates during the latter stages of their respective processes for constructing the core structure.

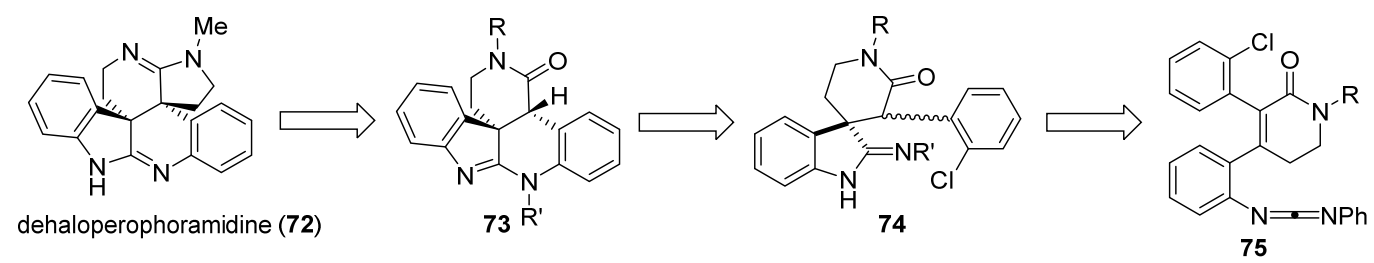

Scheme 13. Retrosynthesis of dehaloperophoramidine (72)

Carbodiimide 75, which contains a tetrasubstituted olefin, was synthesized from the commercially available ethyl $\mathrm{N}$-(benzylamino)propionate (76) (Scheme 14). The introduction of the ethyl malonyl moiety followed by the Dieckmann condensation of the resulting amide gave lactam 77, which was converted to $\beta$-keto-lactam $\mathbf{7 8}$ via a one-pot hydrolysis decarboxylation reaction. Treatment of $\mathbf{7 8}$ with $\mathrm{N}$-phenyl trifluoromethanesulfonimide $\left(\mathrm{Tf}_{2} \mathrm{NPh}\right)$ and $\mathrm{Et}_{3} \mathrm{~N}$ gave the corresponding vinyl triflate 79. The Suzuki coupling reaction of triflate $\mathbf{7 9}$ with boronic acid $\mathbf{8 0}^{\mathbf{7 6}}$ gave the biaryl product $\mathbf{8 1}$, which was sequentially brominated and trityl (Tr)-protected to give 82. The second Suzuki coupling of lactam 82 with 2-chlorophenyl boronic acid $\mathbf{8 3}$ proceeded smoothly to give the tetrasubstituted olefin, which was treated with trifluoroacetic acid to give aniline $\mathbf{8 4}$ in 50\% yield from 82. Two carbodiimides (75a and 75b) bearing a $p$-methoxyphenyl (PMP) or $p$-methoxybenzyl (PMB) group were synthesized to determine the effect of different protecting groups on the palladium-catalyzed intramolecular $\mathrm{C}-\mathrm{N}$ bond forming reaction. These carbodiimides were prepared by the treatment of compound $\mathbf{8 4}$ with an appropriate aryl 
isocyanate followed by the dehydration of the resulting urea with triphenylphosphine and carbon tetrabromide. The resulting carbodiimides $\mathbf{7 5 a}$ and $\mathbf{7 5 b}$ were found to be stable at room temperature, whereas carbodiimide 65, which did not possess an $\alpha$-substituent on its $\alpha, \beta$-unsaturated lactam, was gradually converted to 2 -aminoquinoline through an undesired $6 \pi$ electrocyclic reaction under the same conditions (Scheme 11 and Table 7). ${ }^{64}$
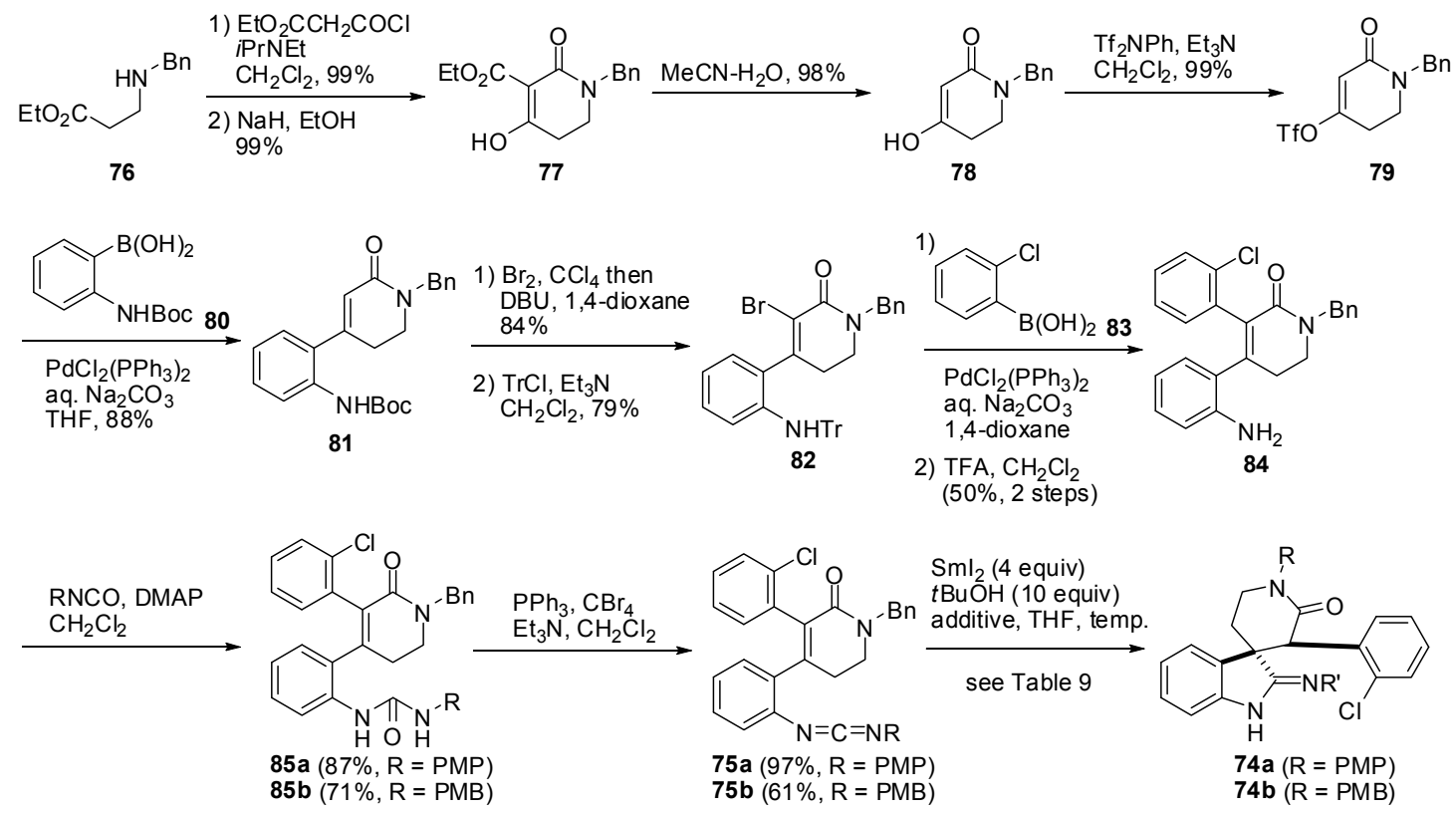

Scheme 14. Synthesis of spiro-2-iminoindolines $\mathbf{7 4 a}$ and $\mathbf{7 4 b}$

With carbodiimides $\mathbf{7 5 a}$ and $\mathbf{7 5 b}$ bearing tetrasubstituted olefins in hand, we proceeded to investigate their performance in the $\mathrm{SmI}_{2}$-mediated reductive cyclization. The reductive cyclization of the $N$-PMP carbodiimide 75a with $\mathrm{SmI}_{2}$ in the presence of $t$-butanol at room temperature proceeded smoothly to give spiro-2-iminoindoline 74a in 86\% yield (Scheme 14 and Table 9, entry 1). ${ }^{1} \mathrm{H}$ NMR and X-ray crystallography indicated that 74a existed as a mixture of amidine-tautomers, with the ratio of the tautomers depending on the solvent. X-Ray crystallographic analysis of $\mathbf{7 4 a}$ also revealed that the two aryl groups on the 2-piperidinone ring were in a syn configuration (Figure 5, left). The stereoselectivity of this reaction was attributed to the selective protonation of the samarium enolate $\mathbf{8 5}$ from the same side as the PMP-imine moiety, which was less sterically hindered (Figure 5, right). We also investigated the reductive cyclization of $\mathrm{N}$-PMB carbodiimide $\mathbf{7 5 b}$ under the optimal conditions. Unfortunately, the reaction did not proceed at room temperature or $60{ }^{\circ} \mathrm{C}$, with the starting material $\mathbf{7 5 b}$ being recovered in both cases (Table 9, entries 2 and 3). Pleasingly, the use of HMPA as a co-solvent, which is generally used to increase the reduction potential of $\mathrm{SmI}_{2},{ }^{65}$ allowed for the desired cyclization reaction to proceed at room temperature to give iminoindoline $\mathbf{7 4 b}$ in $90 \%$ yield (Table 9, entry 4). 
Table 9. Reductive cyclization of carbodiimide $\mathbf{7 5 a}$ and $\mathbf{7 5 b}$

\begin{tabular}{ccccc}
\hline entry & substrate & additives & temp & results \\
\hline 1 & $\mathbf{7 5 a}$ & none & $\mathrm{rt}$ & $86 \%{ }^{[\mathrm{a}]}$ \\
2 & $\mathbf{7 5 b}$ & none & $\mathrm{rt}$ & no reaction \\
3 & $\mathbf{7 5 b}$ & none & $60{ }^{\circ} \mathrm{C}$ & no reaction \\
4 & $\mathbf{7 5 b}$ & HMPA $(10 \% \mathrm{vol})$ & $\mathrm{rt}$ & $90 \%$ \\
\hline
\end{tabular}

[a] 2.8 equiv of $\mathrm{SmI}_{2}$ was used.
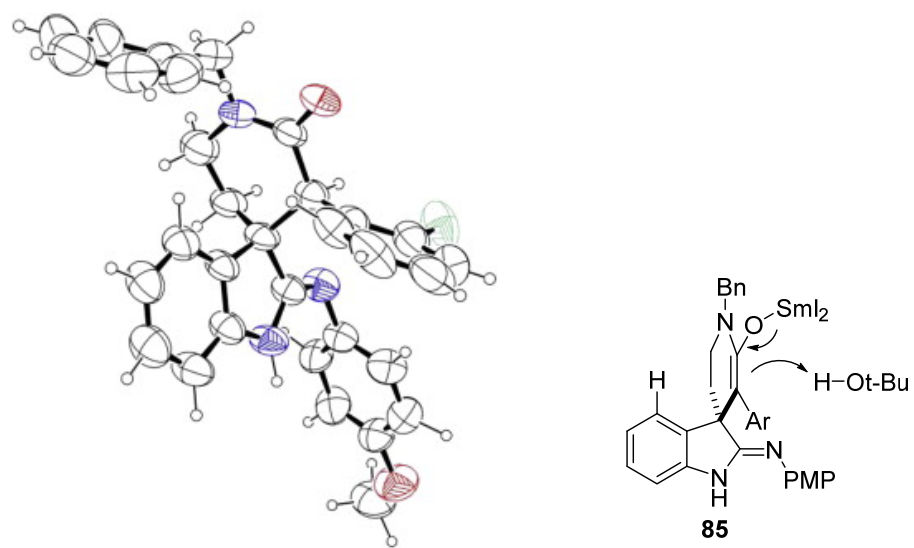

Figure 5. X-Ray structure of 74a (left) and the protonation of samarium enolate $\mathbf{8 5}$ (right)

The epimerization of the $\alpha$-position of the lactam was investigated prior to evaluating the intramolecular palladium-catalyzed aryl amidination ${ }^{77}$ because the spiro-2-iminoindolines $\mathbf{7 4 a}$ and $\mathbf{7 4 b}$ were much less likely than the other diastereomers to undergo the cyclization based on their conformation. Treatment of spiro-2-iminoindoline 74a with sodium $t$-butoxide in DMA at room temperature resulted in no reaction, whereas $74 \mathrm{c}$ was obtained by epimerization after $2 \mathrm{~h}$ at $60{ }^{\circ} \mathrm{C}$, which was observed by ${ }^{1} \mathrm{H}$ NMR analysis (Scheme 15). Surprisingly, the desired cyclization reaction occurred to give the pentacyclic compound 73a when the material was heated at $120^{\circ} \mathrm{C}$ for $24 \mathrm{~h}$ (Table 10 , entry 1 ). While we did not extensively investigate these transition-metal-free conditions, we suspected a involvement of a trace amount of palladium catalyst under these conditions. Several alkylphosphine ligands were screened to develop a concise cyclization reaction for the palladium catalyzed amidination of compound 74a. Although the use of $\mathrm{Ad}_{2} \mathrm{PBu}$ in the presence of $\mathrm{Pd}(\mathrm{OAc})_{2}$ did not give satisfactory results (Table 10 , entry 2$), \mathrm{Bu}_{3} \mathrm{P} \cdot \mathrm{HBF}_{4}$, CyJohnPhos, DavePhos, and tricyclohexylphosphine $\left(\mathrm{Cy}_{3} \mathrm{P}\right)$ led to improvements in the yield up to $78 \%$ (Table 10, entries 3-6). Notably, $\mathrm{Cy}_{3} \mathrm{P}$, which was identified as the best ligand for the reaction, also led to a significant increase in the reaction rate $(17 \mathrm{~h}, 78 \%$ yield) (Table 10, entry 6$)$. Decreasing the amounts of palladium catalyst and $\mathrm{Cy}_{3} \mathrm{P}$ led to an increase in the yield up to $86 \%$ (Table 10, entry 7). The newly generated stereochemistry in pentacycle 73a was determined by 2D NMR analyses, including NOESY 
experiments (Figure 6). In sharp contrast, the application of these optimized conditions to the $N$-PMB-protected iminoindoline 74b did not give the cyclized product. In this particular case, the starting material was recovered unchanged, and the differences in the reactivities of the two substrates were attributed to differences in the electronic properties. However, it is important to mention that a detailed mechanism for this cyclization reaction has not yet been determined.

The pentacyclic skeleton of perophoramidine (57) was successfully constructed by the $\mathrm{SmI}_{2}$-mediated reductive cyclization of carbodiimide 75a bearing a tetrasubstituted olefin followed by a palladium-catalyzed intramolecular $\mathrm{C}-\mathrm{N}$ bond formation. ${ }^{48}$ The resulting pentacyclic compound 73a was synthetically equivalent to Rainier's pentacyclic amidine, which was used as an intermediate for dehaloperophoramidine. ${ }^{71}$ This newly developed and unique strategy provided a novel platform for synthesizing natural products containing an amidine moiety.

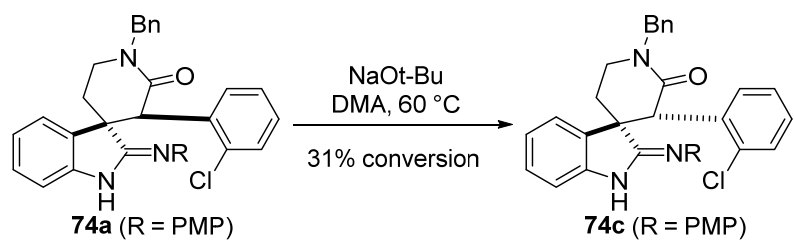

Scheme 15. Isomerization of iminoindoline 74a

Table 10. Intramolecular aryl amidination of iminoindoline 73a

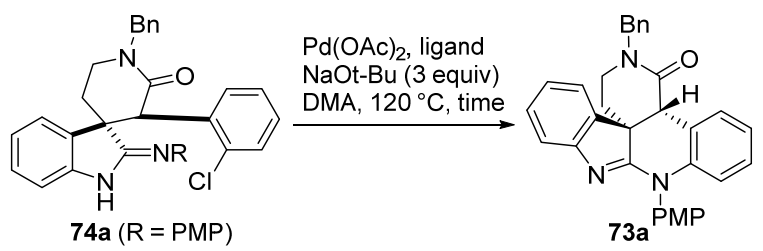

\begin{tabular}{ccccc}
\hline entry & $\mathrm{Pd}(\mathrm{OAc})_{2}$ & ligand $(\mathrm{mol} \%)$ & Time $(\mathrm{h})$ & Yield (\%) \\
\hline 1 & none & none & 24 & 27 \\
2 & $10 \mathrm{~mol} \%$ & $\mathrm{Ad}_{2} \mathrm{PnBu}(20)$ & 24 & 31 \\
3 & $10 \mathrm{~mol} \%$ & $t \mathrm{Bu}_{3} \mathrm{P} \cdot \mathrm{HBF}_{4}(20)$ & 24 & 63 \\
4 & $10 \mathrm{~mol} \%$ & $\mathrm{Cyclohexyl} \mathrm{JohnPhos}(20)_{2}$ & 24 & 66 \\
5 & $10 \mathrm{~mol} \%$ & Davephos $(20)$ & 24 & 70 \\
6 & $10 \mathrm{~mol} \%$ & $\mathrm{Cy}_{3} \mathrm{P} \cdot \mathrm{HBF}_{4}(20)$ & 17 & 78 \\
7 & $5 \mathrm{~mol} \%$ & $\mathrm{Cy}_{3} \mathrm{P} \cdot \mathrm{HBF}_{4}(10)$ & 17 & 86 \\
\hline
\end{tabular}




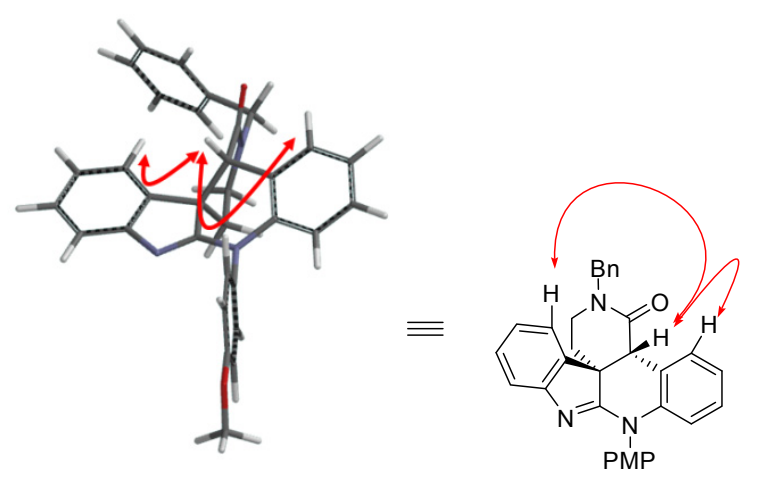

Figure 6. NOESY correlation of pentacycle 73a

\section{SUMMARY}

We have been heavily involved in developing novel synthetic strategies for constructing spirooxindoles based on the formation of the $\mathrm{C} 2-\mathrm{C} 3$ bond. Our work in this area has led to the development of a palladium-catalyzed domino reaction for the formation of spirooxindoles, as well as an alternative strategy involving the palladium-catalyzed carbosilylation of carbamoyl chlorides bearing a 1,3-diene moiety. Using the former method, we successfully completed a formal synthesis of elacomine and isoelacomine. The combination of our newly developed domino palladium-catalyzed carbosilylation of 1,3-dienes with a Sakurai-type cyclization reaction allowed for the successful construction of spirooxindoles fused with tetrahydropyran, piperidine, and five-membered carbocycles, with control over two or three contiguous stereocenters.

Inspired by these newly developed methods for constructing spirooxindoles, we also established a $\mathrm{SmI}_{2}$-mediated process involving the intramolecular reductive cyclization of carbodiimides, which allowed for the synthesis of 2-iminoindolines bearing a quaternary-carbon center at their C3 position. This unique synthetic method was combined with a palladium-catalyzed intramolecular $\mathrm{C}-\mathrm{N}$ bond formation reaction to allow for the effective construction of the core structure of perophoramidine, which is a hexacyclic alkaloid.

We believe that these synthetic strategies represent a powerful addition to the plethora of synthetic transformations already available to synthetic chemists, and could be readily applied to the synthesis of complex spirooxindole- and iminoindoline-containing natural products. Further work towards the application of these reactions is currently underway in our laboratory and will be reported in due course. ${ }^{78}$

\section{ACKNOWLEDGEMENTS}

The studies described in this review were performed by Dr. Y. Yasui, Dr. H. Kamisaki, Dr. S. M. Hande, Dr. T. Ishida, Mr. T. Nanjo and Mr. M. Nakajima, and we are deeply indebted to them for all of their hard work. These studies were supported in part by Grants-in-Aid for Scientific Research (B) (Y.T.), Young 
Scientists (B) (C.T.), and Young Scientists (Start-up) (Y.Y.), "Targeted Proteins Research Program" and

"Platform for Drug Design, Discovery and Development" from the Ministry of Education, Culture, Sports, Science and Technology of Japan, and JSPS Research Fellowship for Young Scientists (T.I.).

\section{REFERENCES (AND NOTES)}

1. For selected reviews on natural products containing indoles and related skeletons, see: (a) J. S. Bindra, 'The Alkaloids', Vol. 14, ed. by R. H. F. Manske, Academic Press, Inc., New York, 1973, pp.84-121; (b) M. Ishikura and K. Yamada, Nat. Prod. Rep., 2009, 26, 803; (c) A. J. Kochanowska-Karamyan and M. T. Hamann, Chem. Rev., 2010, 110, 4489.

2. T. Kosuge, K. Tsuji, K. Hirai, T. Fukuyama, H. Nukaya, and H. Ishida, Chem. Pharm. Bull., 1985, 33, 2890.

3. (a) R. C. Elderfield and R. E. Gilman, Phytochemistry, 1972, 11, 339; (b) S. Cheenpracha, T. Ritthiwigrom, and S. Laphookhieo, J. Nat. Prod., 2013, 76, 723.

4. C.-B. Cui, H. Kakeya, and H. Osada, Tetrahedron, 1996, 52, 12651.

5. X.-H. Cai, Q.-G. Tan, Y.-P. Liu, T. Feng, Z.-Z. Du, W.-Q. Li, and X.-D. Luo, Org. Lett., 2008, 10, 577.

6. $\quad$ K.-H. Lim and T.-S. Kam, Tetrahedron Lett., 2006, 47, 8653.

7. (a) G. W. A. Slywka, Ph. D. Thesis, The University of Alberta, Edmonton (1969); (b) M. N. G. James and G. J. B. Williams, Can. J. Chem., 1972, 50, 2407.

8. B. S. Joshi, P. G. Rao, D. Rogers, B. P. Singri, and D. J. Williams, Indian J. Chem. Sect. B, 1984, 23B, 101 .

9. (a) T. G. Wormley, Am. J. Pharm., 1870, 42, 1; (b) F. M. Lovell, R. Pepinsky and A. J. C. Wilson, Tetrahedron Lett., 1959, 1, 1; (c) H. Conroy and J. K. Chakrabarti, Tetrahedron Lett., 1959, 1, 6.

10. For recent examples, see: (a) A. Fensome, W. R. Adams, A. L. Adams, T. J. Berrodin, J. Cohen, C. Huselton, A. Illenberger, J. C. Kern, V. A. Hudak, M. A. Marella, E. G. Melenski, C. C. McComas, C. A. Mugford, O. D. Slayden, M. Yudt, Z. Zhang, P. Zhang, Y. Zhu, R. C. Winneker, and J. E. Wrobel, J. Med. Chem., 2008, 51, 1861; (b) N. Teno, K. Masuya, T. Ehara, T. Kosaka, T. Miyake, O. Irie, Y. Hitomi, N. Matsuura, I. Umemura, G. Iwasaki, H. Fukaya, K. Toriyama, N. Uchiyama, K. Nonomura, I. Sugiyama, and M. Kometani, J. Med. Chem., 2008, 51, 5459.

11. (a) A. B. Dounay and L. E. Overman, Chem. Rev., 2003, 103, 2945; (b) H. Lin and S. J. Danishefsky, Angew. Chem. Int. Ed., 2003, 42, 36; (c) C. Marti and E. M. Carreira, Eur. J. Org. Chem., 2003, 2209; (d) A. Steven and L. E. Overman, Angew. Chem. Int. Ed., 2007, 46, 5488; (e) C. V. Galliford and K. A. Scheidt, Angew. Chem. Int. Ed., 2007, 46, 8748; (f) B. M. Trost and M. K. Brennan, Synthesis, 2009, 3003; (g) F. Zhou, Y.-L. Liu, and J. Zhou, Adv. Synth. Catal., 2010, 352, 
1381; (h) R. Dalpozzo, G. Bartoli, and G. Bencivenni, Chem. Soc. Rev., 2012, 41, 7247; (i) N. R. Ball-Jones, J. J. Badillo, and A. K. Franz, Org. Biomol. Chem., 2012, 10, 5165.

12. D. Lizos, R. Tripoli, and J. A. Murphy, Chem. Commun., 2001, 2732.

13. (a) L. E. Overman and M. D. Rosen, Angew. Chem. Int. Ed., 2000, 39, 4596; (b) L. E. Overman and M. D. Rosen, Tetrahedron, 2010, 66, 6514.

14. S. D. Edmondson and S. J. Danishefsky, Angew. Chem. Int. Ed., 1998, 37, 1138.

15. (a) W. G. B. van Henugouwen, R. M. Fieseler, F. P. J. T. Rutjes, and H. Hiemstra, Angew. Chem. Int. Ed., 1999, 38, 2214; (b) W. G. B. van Henugouwen, R. M. Fieseler, F. P. J. T. Rutjes, and H. Hiemstra, J. Org. Chem., 2000, 65, 8317.

16. F. Von Nussbaum and S. J. Danishefsky, Angew. Chem. Int. Ed., 2000, 39, 2178.

17. P. B. Alper, C. Meyers, A. Lerchner, D. R. Siegel, and E. M. Carreira, Angew. Chem. Int. Ed., 1999, 38, 3186.

18. P. R. Sebahar and R. M. Williams, J. Am. Chem. Soc., 2000, 122, 5666.

19. (a) Y. Kobayashi, H. Kamisaki, R. Yanada, and Y. Takemoto, Org. Lett., 2006, 8, 2711; (b) Y. Kobayashi, H. Kamisaki, H. Takeda, Y. Yasui, R. Yanada, and Y. Takemoto, Tetrahedron, 2007, 63, 2978; (c) Y. Yasui, H. Kamisaki, and Y. Takemoto, Org. Lett., 2008, 10, 3303; (d) Y. Yasui, H. Kamisaki, T. Ishida, and Y. Takemoto, Tetrahedron, 2010, 66, 1980.

20. H. Kamisaki, Y. Yasui, and Y. Takemoto, Tetrahedron. Lett., 2009, 50, 2589.

21. H. Kamisaki, T. Nanjo, C. Tsukano, and Y. Takemoto, Chem. Eur. J., 2011, 17, 626.

22. S. M. Hande, M. Nakajima, H. Kamisaki, C. Tsukano, and Y. Takemoto, Org. Lett., 2011, 13, 1828.

23. (a) R. F. Heck, J. Am. Chem. Soc., 1963, 85, 3381; (b) S. D. Robinson and B. L. Shaw, J. Chem. Soc., 1963, 4806; (c) R. M. Rowe and D. A. White, J. Chem. Soc., 1967, 1451.

24. For reports concerning the addition of nitrogen-based nucleophiles to conjugated dienes catalyzed by palladium(0), see: (a) B. A. Patel, J. E. Dickerson, and R. F. Heck, J. Org. Chem., 1978, 43, 5018; (b) F. G. Stakem and R. F. Heck, J. Org. Chem., 1980, 45, 3584.

25. The carbamoyl chloride was employed by Grigg and co-workers in their synthesis of 3,3-disubstituted oxindoles using palladium catalyst, see: (a) M. R. Fielding, R. Grigg, and C. J. Urch, Chem. Commun., 2000, 2239; (b) J. Anwar, M. R. Fielding, R. Grigg, V. Sridharan, and C. J. Urch, J. Organomet. Chem., 2006, 691, 1476

26. E. Piers and R. D. Tillyer, Can. J. Chem., 1996, 74, 2048.

27. C. Pellegrim, M. Eber, and H.-J. Borschberg, Helv. Chim. Acta, 1996, 79, 151.

28. F. Y. Miyake, K. Yakushijin, and D. A. Horne, Org. Lett., 2004, 6, 711.

29. J. D. White, Y. Li, and D. C. Ihle, J. Org. Chem., 2010, 75, 3569.

30. For reviews of the Heck reaction, see: (a) W. Cabri and I. Candiani, Acc. Chem. Res., 1995, 28, 2; 
(b) I. P. Beletskaya and A. V. Cheprakov, Chem. Rev., 2000, 100, 3009; (c) J. T. Link Org. React., $2002, \mathbf{6 0}, 157$.

31. (a) H. Qin, N. Yamagiwa, S. Matsunaga, and M. Shibasaki, J. Am. Chem. Soc., 2006, 128, 1611; (b)

H. Qin, N. Yamagiwa, S. Matsunaga, and M. Shibasaki Chem. Asian J., 2007, 2, 150.

32. (a) H. Wei, G. Qian, Y. Xia, K. Li, Y. Li, and W. Li, Eur. J. Org. Chem., 2007, 4471; (b) X. Cheng, Y. Xia, H. Wei, B. Xu, C. Zhang, Y. Li, G. Qian, X. Zhang, K. Li, and W. Li, Eur. J. Org. Chem., 2008, 1929.

33. I. Beletskaya and C. Moberg, Chem. Rev., 2006, 106, 2320.

34. (a) Y. Sato, N. Saito, and M. Mori, Chem. Lett., 2002, 38, 18; (b) N. Saito, M. Mori, and Y. Sato, J. Organomet. Chem., 2007, 692, 460.

35. C.-M. Yu, J. Youn, S.-K. Yoon, and Y.-T. Hong, Org. Lett., 2005, 7, 4507.

36. $\mathrm{Rh}$ catalysts were employed for the silylation of aryl and alkenyl cyanides and the borylative cyclization of alkynylaryl isocyanates involving the cleavage of $\mathrm{Si}-\mathrm{Si}$ or $\mathrm{B}-\mathrm{B}$ bonds, see: (a) M. Tobisu, Y. Kita, and N. Chatani, J. Am. Chem. Soc., 2006, 128, 8152; (b) T. Miura, Y. Takahashi, and M. Murakami, Org. Lett., 2008, 9, 1743.

37. For reports concerning the intermolecular carbometallation of dienes, see: (a) Y. Obora, Y. Tsuji, and T. Kawamura, J. Am. Chem. Soc., 1993, 115, 10414; (b) Y. Obora, Y. Tsuji, and T. Kawamura, J. Am. Chem. Soc., 1995, 117, 9814; (c) F.-Y. Yang, M. Shanmugasundaram, S.-Y. Chuang, P.-J. Ku, M.-Y. Wu, and C.-H. Cheng, J. Am. Chem. Soc., 2003, 125, 12576.

38. For related reviews, see: (a) D. R. Adams and S. P. Bhatnagar, Synthesis, 1977, 661; (b) T. Mukaiyama and M. Murakami, Synthesis, 1987, 1043.

39. L. E. Overman and D. A. Watson, J. Org. Chem., 2006, 71, 2587.

40. While the mechanism of the palladium-catalyzed carbosilylation has not been disclosed, we assumed the two plausible mechanisms. One is shown in Scheme 8. The other plausible pathway would commence with the oxidative addition of the carbamoyl chloride to a palladium catalyst. Insertion into the diene moiety would be followed by transmetallation with $\mathrm{Me}_{3} \mathrm{SiSiMe}_{3}$ and reductive elimination to give the product. We previously reported (refs. 19d, 20 and 21) that the addition of $\mathrm{PPh}_{3}$ was beneficial for the oxidative addition of the carbamoyl chloride to palladium, however, the addition of $\mathrm{PPh}_{3}$ in this case proved to be detrimental to the cyclization (Table 4, entries 8 and 9), and it was therefore assumed that the reaction proceeded via a bismetallative process.

41. (a) A. Numata, C. Takahashi, Y. Ito, T. Takada, K. Kawai, Y. Usami, E. Matsumura, M. Imachi, T. Ito, and T. Hasegawa, Tetrahedron Lett., 1993, 34, 2355; (b) H. Hayashi, H. Matsumoto, and K. Akiyama, Biosci. Biotechnol. Biochem., 2004, 68, 753; (c) R. Jadulco, R. A. Edrada, R. Ebel, A. 
Berg, K. Schaumann, V. Wray, K. Steube, and P. Proksch, J. Nat. Prod., 2004, 67, 78; (d) P. W. Dalsgaard, J. W. Blunt, M. H. G. Munro, J. C. Frisvad, and C. Christophersen, J. Nat. Prod., 2005, 68, 258; (e) B. Andersen, J. Smedsgaard, and J. C. Frisvad, J. Agric. Food Chem., 2004, 52, 2421; (f) L. J. Wigley, P. G. Mantle, and D. A. Perry, Phytochemistry, 2006, 67, 561.

42. S. M. Verbitski, C. L. Mayne, R. A. Davis, G. P. Concepcion, and C. M. Ireland, J. Org. Chem., $2002,67,7124$.

43. J. S. Carlé and C. Christophersen, J. Org. Chem., 1981, 46, 3440

44. N. Koyama, Y. Inoue, M. Sekine, Y. Hayakawa, H. Homma, S. Ōmura, and H. Tomoda, Org. Lett., $2008,10,5273$.

45. A. Hirano, Y. Iwai, R. Masuma, K. Tei, and S. Ōmura, J. Antibiot., 1979, 32, 781.

46. C. Bunders, J. Cavanagh, and C. Melander, Org. Biomol. Chem., 2011, 9, 5476.

47. T. Ishida, C. Tsukano, and Y. Takemoto, Chem. Lett., 2012, 41, 44.

48. T. Ishida and Y. Takemoto, Tetrahedron, 2013, 69, 4517.

49. (a) T. Kawasaki, R. Terashima, K. Sakaguchi, H. Sekiguchi, and M. Sakamoto, Tetrahedron Lett., 1996, 37, 7525; (b) Y. Jiang, J. Zhao, and L. Hu, Tetrahedron Lett., 2002, 43, 4589; (c) Y. A. O. Barbosa, D. J. Hart, and N. A. Magomedov, Tetrahedron, 2006, 62, 8748; (d) A. Sabahi, A. Novikov, and J. D. Rainier, Angew. Chem. Int. Ed., 2006, 45, 4317; (e) M. Ohno, T. F. Spande, and B. Witkop, J. Am. Chem. Soc., 1968, 90, 6521.

50. D. Aburano, T. Yoshida, N. Miyakoshi, and C. Mukai, J. Org. Chem., 2007, 72, 6878.

51. B. Witulski, C. Alayrac, and L. Tevzadze-Saeftel, Angew. Chem. Int. Ed., 2003, $42,4257$.

52. M. K. G. Mekhael and H. Heimgartner, Helv. Chim. Acta, 2003, 86, 2805.

53. D. Dhanak, S. Neidle, and C. B. Reese, Tetrahedron Lett., 1985, 26, 2017.

54. J. R. Fuchs and R. L. Funk, J. Am. Chem. Soc., 2004, 126, 5068.

55. Y. Matsuda, M. Kitajima, and H. Takayama, Org. Lett., 2008, 10, 125.

56. A. Williams and I. T. Ibrahim, Chem. Rev., 1981, 81, 589.

57. (a) W. Ahrens and A. Berndt, Tetrahedron Lett., 1974, 15, 3741; (b) G. Brunton, J. F. Taylor, and K. U. Ingold, J. Am. Chem. Soc., 1976, 98, 4879.

58. J. L. Namy, P. Girard, and H. B. Kagan, New J. Chem., 1977, 1, 5.

59. For reviews concerning $\mathrm{SmI}_{2}$ mediated reactions, see: (a) G. A. Molander and C. R. Harris, Chem. Rev., 1996, 96, 307; (b) K. Gopalaiah and H. B. Kagan, New J. Chem., 2008, 32, 607.

60. (a) D. J. Edmonds, D. Johnston, and D. J. Procter, Chem. Rev., 2004, 104, 3371; (b) K. C. Nicolaou, S. P. Ellery, and J. S. Chen, Angew. Chem. Int. Ed., 2009, 48, 7140.

61. (a) J. L. Namy, J. Souppe, and H. B. Kagan, Tetrahedron Lett., 1983, 24, 765; (b) S. Fukuzawa, A. Nakanishi, T. Fujinami, and S. Sakai, Chem. Commun., 1986, 624; (c) T. Imamoto and S. 
Nishimura, Chem. Lett., 1990, 19, 1141; (d) J. Inanaga, Y. Handa, T. Tabuchi, K. Otsubo, M. Yamaguchi, and T. Hanamoto, Tetrahedron Lett., 1991, 32, 6557; (e) N. Taniguchi T. Hata, and M. Uemura, Angew. Chem. Int. Ed., 1999, 38, 1232; (f) Y. H. Kim, H. S. Park, and D. W. Kwon, Synth. Commun., 1998, 28, 4517; (g) J. M. Ready, S. E. Reisman, M. Hirata, M. M. Weiss, K. Tamaki, T. V. Ovaska, and J. L. Wood, Angew. Chem. Int. Ed., 2004, 43, 1270.

62. For a report concerning the dimerization of carbodiimide by samarocene, see: M. Deng, Y. Yao, Y. Zhang, and Q. Shen, Chem. Commun., 2004, 2742.

63. T. Saito, K. Tsuda, and Y. Saito, Tetrahedron Lett., 1996, 37, 209.

64. (a) T. Saito, H. Ohmori, E. Furuno, and S. Motoki, Chem. Commun., 1992, 22; (b) P. Molina, M. Alajarín, A. Vidal, and P. Sánchez-Andrada, J. Org. Chem., 1992, 57, 929.

65. J. Inanaga, M. Ishikawa, and M. Yamaguchi, Chem. Lett., 1987, 16,1485.

66. (a) R. S. Miller, J. M. Sealy, M. Shabangi, M. L. Kuhlman, J. R. Fuchs, and R. A. Flowers II, J. Am. Chem. Soc., 2000, 122, 7718; (b) F. Machrouhi, B. Hmann, J. L. Namy, and H. B. Kagan, Synlett, 1996, 633.

67. (a) J. R. Fuchs and R. L. Funk, J. Am. Chem. Soc., 2004, 126, 5068; (b) S. L. Crawley and R. L. Funk, Org. Lett., 2003, 5, 3169.

68. (a) H. Wu, F. Xue, X. Xiao, and Y. Qin, J. Am. Chem. Soc., 2010, 132, 14052; (b) J. Yang, H. Song, X. Xiao, J. Wang, and Y. Qin, Org. Lett., 2006, 8, 2187; (c) H. Wu, X. Xiao, and Y. Qin, Synlett, $2011,907$.

69. (a) J. A. May, R. K. Zeidan, and B. M. Stoltz, Tetrahedron Lett., 2003, 44, 1203; (b) S.-J. Han, F. Vogt, S. Krishnan, J. A. May, M. Gatti, S. C. Virgil, and B. M. Stoltz, Org. Lett., 2014, 16, 3316.

70. (a) G. D. Artman III and S. M. Weinreb, Org. Lett., 2003, 5, 1523; (b) J. H. Seo, G. D. Artman III, and S. M. Weinreb, J. Org. Chem., 2006, 71, 8891; (c) M. A. Evans, J. R. Sacher, and S. M. Weinreb, Tetrahedron, 2009, 65, 6712.

71. A. Sabahi, A. Novikov, and J. D. Rainier, Angew. Chem. Int. Ed., 2006, 45, 4317.

72. B. M. Trost and Y. Zhang, Chem. Eur. J., 2011, 17, 2916.

73. Y. Du, H. Wu, H. Song, Y. Qin, and D. Zhang, Chin. J. Chem., 2012, 30, 1970.

74. A. W. Schammel, G. Chiou, and N. K. Garg, Org. Lett., 2012, 14, 4556.

75. H. Zhang, L. Hong, H. Kang, and R. Wang, J. Am. Chem. Soc., 2013, 135, 14098.

76. M. J. Sharp and V. Snieckus, Tetrahedron Lett., 1985, 26, 5997.

77. (a) C. B. Brain and T. Brunton, Tetrahedron Lett., 2002, 43, 1893; (b) M. A. McGowan, C. Z. McAvoy, and S. L. Buchwald, Org. Lett., 2012, 14, 3800.

78. For our most recent papers concerning the synthesis of indoles, oxindoles and iminoindolines, see: (a) C. Tsukano, M. Okuno, and Y. Takemoto, Angew. Chem. Int. Ed., 2012, 51, 2763; (b) T. Nanjo, 
C. Tsukano, and Y. Takemoto, Org. Lett., 2012, 14, 4270; (c) C. Tsukano, M. Okuno, and Y. Takemoto, Chem. Lett., 2013, 42, 753; (d) T. Nanjo, S. Yamamoto, C. Tsukano, and Y. Takemoto, Org. Lett., 2013, 15, 3754; (e) T. Ishida, H. Ikota, K. Kurahashi, C. Tsukano, and Y. Takemoto, Angew. Chem. Int. Ed., 2013, 52, 10204; (f) T. Nanjo, C. Tsukano, and Y. Takemoto, Synlett, 2014, 25, 1473; (g) C. Tsukano, M. Okuno, H. Nishiguchi, and Y. Takemoto, Adv. Synth. Catal., 2014, 356, 1533.

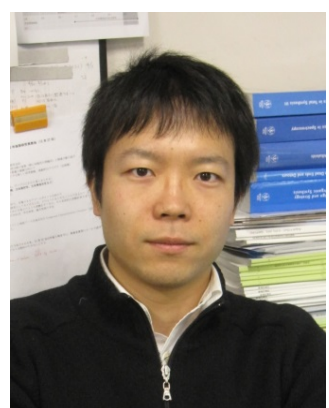

Chihiro Tsukano studied chemistry at the Department of Chemistry at Tokyo University under the guidance by Prof. Kazuo Tachibana. After received B.Sc and M.Sc. degrees, he moved to Tohoku University and received his Ph. D. in 2006 under the guidance by Prof. Makoto Sasaki. After postdoctoral studies (2006-2008 under Prof. Samuel J. Danishefsky, Memorial Sloan-Kettering Cancer Center, New York), he joined the Department of Chemistry at Tohoku University and worked in the laboratory of Prof. Masahiro Hirama. In 2009 he moved to Graduate School of Pharmaceutical Sciences, Kyoto University and worked with Prof. Yoshiji Takemoto as Assistant Professor. In 2014 he promoted to Lecturer in the same group. His research interests center on the area of development synthetic methodology and natural product synthesis.

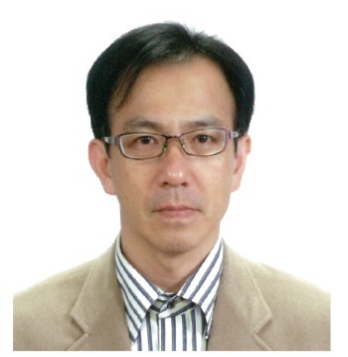

Yoshiji Takemoto is a professor at the Graduate School of Pharmaceutical Sciences, Kyoto University. He received his B.S. (1983), M.S. (1985), and Ph.D. (1988) degrees from Osaka University. He worked as a postdoctoral fellow with Prof. R. A. Holton at Florida State University for 1 year from 1988, and with Dr. S. Terashima at Sagami Chemical Research Center for 1 year from 1989. He joined the Faculty of Pharmaceutical Sciences, Osaka University, as an assistant professor in 1990. He moved to the Graduate School of Pharmaceutical Sciences, Kyoto University, as an associate professor in 1998 and was promoted to professor in 2000. His research interests are in the areas of synthetic organic chemistry, transition metal chemistry, organocatalyst chemistry, and total synthesis of natural products. 